05

\title{
Механизмы возникновения напряжений в тонких пленках и покрытиях
}

\author{
(C) А.Р. Шугуров, А.В. Панин
}

Институт фризики прочности и материаловедения СО РАН, 634055 Томск, Россия

e-mail: shugurov@ispms.tsc.ru

Поступило в Редакцию 31 января 2020 г.

В окончательной редакции 25 марта 2020 г.

Принято к публикации 3 мая 2020 г.

Проведен анализ литературных данных, посвященных причинам развития механических напряжений в эпитаксиальных, поликристаллических и аморфных пленках в процессе их формирования и при различных внешних воздействиях. Описан механизм возникновения внутренних напряжений при гетероэпитаксиальном росте пленок, обусловленных несоответствием постоянных кристаллических решеток пленки и подложки. Показана взаимосвязь между развитием напряжений несоответствия в гетероэпитаксиальных пленках и изменением характера их роста. Рассмотрены модели возникновения сжимающих и растягивающих напряжений в поликристаллических пленках вследствие формирования и коалесценции островков на начальной стадии их роста. Обсуждаются закономерности эволюции внутренних напряжений в сплошных пленках в зависимости от условий их осаждения, а также их химического состава, структуры и механических свойств. Рассмотрены механизмы развития внутренних напряжений в тонких пленках, связанных с образованием в них точечных дефектов, внедрением примесей и фазовыми превращениями, происходящими в процессе осаждения. Подробно рассмотрены внешние факторы, приводящие к возникновению напряжений в тонких пленках в процессе их хранения и эксплуатации.

Ключевые слова: тонкие пленки, покрытия, напряжения, дефекты.

DOI: $10.21883 /$ JTF.2020.12.50417.38-20

\section{Введение}

Тонкие пленки находят все более широкое применение в различных областях науки и техники. Они используются в качестве функциональных покрытий, позволяющих существенно повысить твердость, износостойкость, коррозионную и термическую стойкость конструкционных материалов в авиакосмической промышленности, машиностроении, энергетике, медицинской, химической промышленности и др., а также служат основным конструктивным элементом различных приборов и устройств в микро- и наноэлектронике, солнечной энергетике, оптоэлектронике, медицине и т.д. При этом даже в том случае, когда для выполнения основных функций тонкопленочным структурам не требуется высокая прочность, механические напряжения, которые развиваются в них в процессе осаждения и во время эксплуатации, являются одним из наиболее важных факторов, оказывающих влияние на их эксплуатационные характеристики, надежность и долговечность. Растягивающие напряжения могут вызывать повреждение пленок путем их растрескивания, отслоения от подложки и скалывания (рис. 1,a) [1-5]. Сжимающие напряжения также могут способствовать краевому отслоению и скалыванию пленок [6,7], либо приводить к их короблению (buckling или blistering) или гофрированию (wrinkling) (рис. 1,b,c) [8-12]. Кроме того, напряжения могут обусловливать изменение химического состава и внутренней микроструктуры пленок [13-18], а также существенно влияют на их механические [19-21], трибологические [22-25], электрические [25-29], магнитные [30-32], оптические [33-35], пьезоэлектрические [36], коррозионные свойства [37], биочувствительность [38] и др.

Механические напряжения, возникающие в тонких пленках, можно разделить на две группы [39]. К первой относятся так называемые внутренние напряжения (напряжения роста), которые развиваются непосредственно в процессе формирования пленок и обусловлены изменениями их структуры, химического и фазового состава, происходящими во время их зародышеобразования и роста. Во вторую группу входят внешние напряжения, возникающие в пленках уже после их нанесения на подложку вследствие изменений температуры, химического состава и структуры пленок, воздействия электромагнитного поля, электромиграции, а также механических воздействий (растяжение, сжатие, изгиб), т.е. являются результатом действия на систему пленка-подложка каких-либо внешних сил.

Разделение напряжений на внутренние и внешние является достаточно условным. Один и тот же фактор может способствовать развитию напряжений как в процессе роста пленок, так и после их нанесения. Кроме того, процессы релаксации, протекающие в пленках после осаждения, могут приводить к изменению их напряженного состояния даже в отсутствие каких-либо 

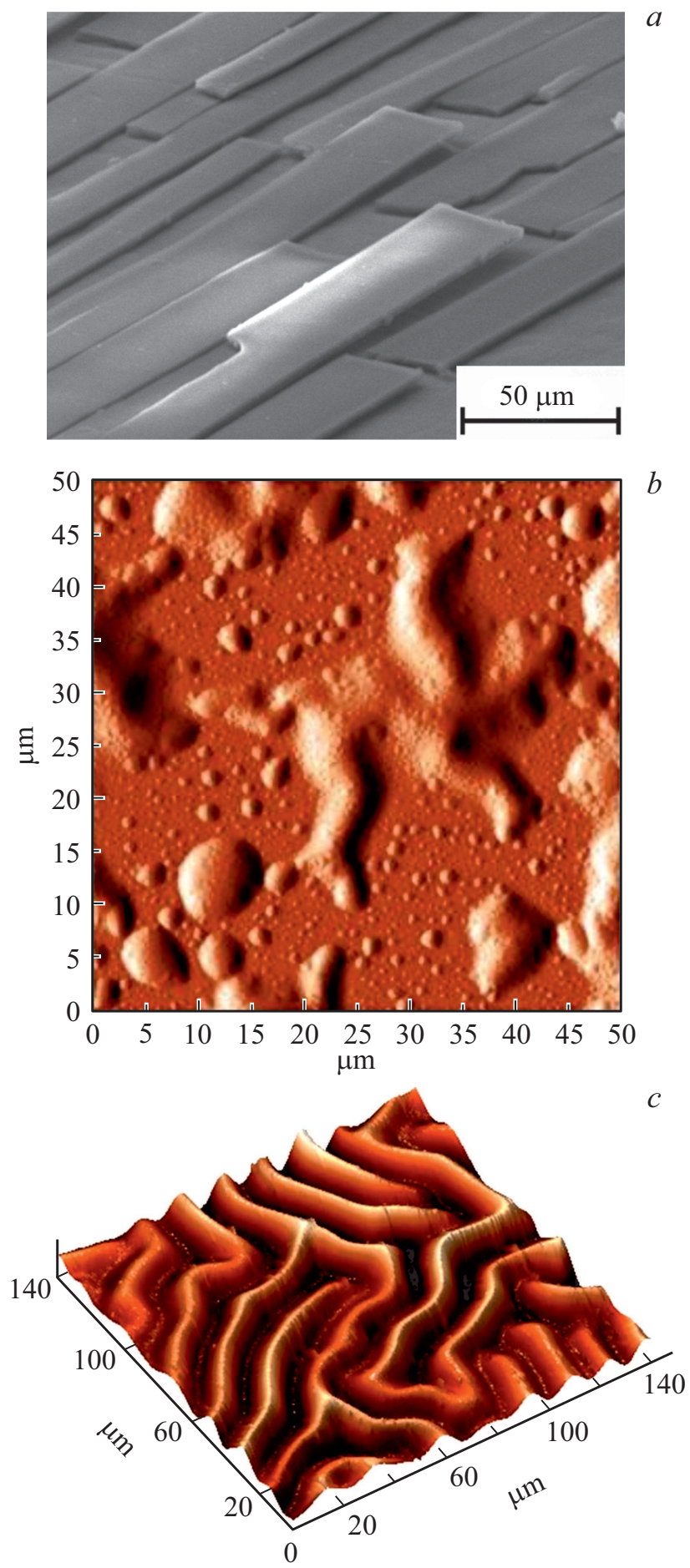

Рис. 1. Деформация и разрушение тонких пленок под действием напряжений: $a-$ растрескивание и скалывание; $b-$ коробление; $c$ - гофрирование.

внешних воздействий. Однако подобная классификация позволяет глубже понять причины и механизмы развития напряжений в пленках и покрытиях.

Во время формирования, хранения и эксплуатации тонкопленочных структур могут одновременно действовать несколько факторов, способствующих развитию в них напряжений. Вклад каждого из этих факторов в общий уровень напряжений существенно зависит как от материалов пленки и подложки, так и от условий воздействия. Так, при пропускании через тонкие металлические пленки электрического тока высокой плотности, наряду с электромиграцией значительное влияние на характер развития в них напряжений оказывает нагрев вследствие выделения джоулева тепла, который зависит от скорости отвода тепла в подложку. Соответствующим образом может изменяться и вклад различных механизмов релаксации напряжений в деформацию и разрушение тонких пленок. Кроме того, поскольку различные факторы могут вызывать развитие в пленках напряжений разного знака (сжимающих или растягивающих), их суммарное действие может способствовать как повышению, так и снижению общего уровня напряжений. Поэтому анализ механизмов развития напряжений в тонких пленках очень важен для разработки эффективных методов управления их напряженным состояниям, а, следовательно, для повышения надежности и долговечности тонкопленочных структур.

В настоящем обзоре систематизированы и обобщены современные представления о фундаментальных физических механизмах развития внутренних и внешних напряжений в тонких пленках. В разд. 1 проведен анализ механизмов возникновения внутренних напряжений. Обсуждаются факторы, которые могут способствовать развитию сжимающих и растягивающих напряжений как в островковых, так и в сплошных пленках. Рассмотрено влияние образования в тонких пленках точечных дефектов, внедрения примесей и фазовых превращений на эволюцию в них внутренних напряжений. В разд. 2 подробно проанализированы причины развития в пленках термических напряжений, а также механизмы развития напряжений в результате эффектов, связанных с процессами электромиграции, воздействием электромагнитного поля, химическими и структурными изменениями, а также при различных механических воздействиях.

\section{1. Внутренние напряжения}

\section{1. Напряжения несоответствия в эпитаксиальных пленках}

Величина и знак внутренних напряжений в тонких пленках зависят от целого ряда факторов, большинство из которых связаны с условиями и методом нанесения пленок на подложку, а также с характером их роста. Так, при гетероэпитаксиальном росте, когда материалы пленки и подложки различны, появление внутренних напряжений главным образом вызвано несоответствием постоянных их кристаллических решеток [40,41]. На поверхности подложки существует потенциальный рельеф, обусловленный распределением атомов в узлах кристаллической решетки. Поэтому первоначально одиночным атомам осаждаемого вещества энергетически выгодно закрепляться в потенциальных ямах, достраивая 


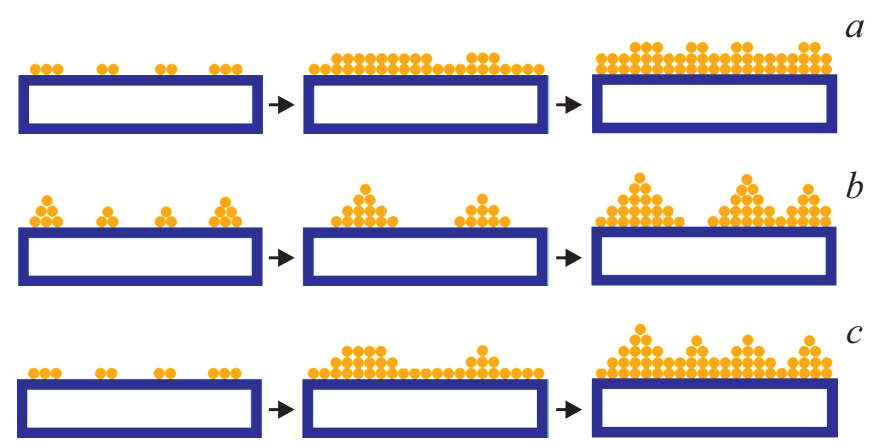

Рис. 2. Механизмы формирования тонких пленок: $a-$ режим Франка-ван дер Мерве (послойный рост); $b-$ режим Фольмера-Вебера (островковый рост); $c$ - режим Странски-Крастанова.

решетку подложки. Однако по мере роста плотности адатомов возникают силы их межатомного взаимодействия, которые стремятся упорядочить атомы пленки в соответствии с периодом решетки, характерным для данного материала. Этому препятствуют силы связи на границе раздела, в результате чего в пленке развиваются внутренние напряжения и происходит деформация системы пленка-подложка, при которой межатомные расстояния в граничных слоях контактирующих материалов становятся одинаковыми.

На начальном этапе роста сплошная гетероэпитаксиальная пленка представляет собой напряженный слой, когерентно сопряженный с подложкой по границе раздела. Если параметры решеток пленки и подложки отличаются незначительно, то псевдоморфный рост пленки, т.е. приспособление ее кристаллической решетки к решетке материала подложки, может продолжаться достаточно долго. При этом реализуется механизм послойного роста пленок Франка-ван дер Мерве [42,43], когда новый слой осаждаемого материала начинает образовываться только после завершения формирования предыдущего (рис. 2,a). Однако так как энергия упругой деформации пленки $W$ пропорциональна ее объему $V$ :

$$
W=\frac{2 \mu_{f}\left(1+v_{f}\right)}{1-v_{f}} \varepsilon^{2} V
$$

(здесь $\mu_{f}-$ модуль сдвига, $v_{f}-$ коэффициент Пуассона пленки, $\varepsilon$ - плоская деформация, возникающая под действием напряжений несоответствия), увеличение толщины нанесенного слоя приводит к быстрому росту $W$. При этом необходимо отметить, что упругая релаксация, обусловленная граничными условиями, может приводить к существенному снижению упругой энергии по сравнению со значением, определяемым выражением (1). Данный эффект наблюдается не только при послойном росте пленок, но и в случае структур с не чисто планарной геометрией [44].

В зависимости от условий нанесения и характеристик пленки и подложки процесс гетероэпитаксиального роста пленки может сопровождаться как ее упругой, так и пластической деформацией [45-47]. Если реализуется пластический механизм релаксации напряжений несоответствия, то в пленке формируются прорастающие дислокации, которые обычно зарождаются на ее свободной поверхности. Распространение данных дислокаций внутрь пленки приводит к возникновению сетки дислокаций несоответствия на ее границе раздела с подложкой.

Упругая релаксация напряжений несоответствия может приводить к огрублению поверхности псевдоморфных пленок и формированию квазипериодического рельефа [48]. Подобный складчатый рельеф, в частности, наблюдался на поверхности пленок $\mathrm{La}_{2 x} \mathrm{Sr}_{x} \mathrm{CuO}_{4}$, нанесенных на подложки $\mathrm{SrTiO}_{3}(100)$ [49], а также при выращивании пленок $\mathrm{GeSi}$ на подложке $\mathrm{Si}$ [50]. При этом чем меньше рассогласование решеток пленки и подложки, т.е. чем меньше исходные напряжения в пленке, тем больше длина волны складок (среднее расстояние между соседними складками) на ее поверхности, и тем позже имеет место потеря устойчивости ровной поверхности.

В ровной пленке упругая релаксация напряжений может происходить только посредством дисторсии, вызывая увеличение ее толщины, а, следовательно, увеличение энергии [51]. Возникновение неровностей на поверхности пленки является более эффективным механизмом упругой релаксации, поскольку в них возможна частичная релаксация постоянной решетки в плоскости пленки к равновесному значению. Релаксация напряжений за счет повышения шероховатости пленки способствует уменьшению ее свободной энергии, однако увеличение площади поверхности обусловливает повышение поверхностной энергии. Как было показано в работах [52-54], плоская поверхность негидростатически напряженного твердого тела является неустойчивой по отношению к возмущениям с определенной длиной волны, которая определяется конкуренцией между его поверхностной энергией и энергией деформации. Поэтому если упругая релаксация напряжений обеспечивает снижение полной свободной энергии пленки, то на ее поверхности возникают складки, высота которых увеличивается со временем.

Когда высота складок становится сравнима с их длиной волны, между складками начинается образование канавок, в то время как в вершинах складок происходит уменьшение кривизны их поверхности [55]. В процессе роста пленок канавки, развивающиеся под действием напряжений, углубляются и могут формировать на поверхности пленки картину, аналогичную растрескиванию [56], достигая границы раздела пленка/подложка, т.е. приводя к потере сплошности пленки. Однако в реальных гетеросистемах развитие канавок наблюдается достаточно редко. Более частым механизмом, обеспечивающим упругую релаксацию напряжений в эпитаксиальных пленках, является распад пленки на отдельные островки.

Послойный рост пленок (режим Франка-ван дер Мерве) реализуется, когда выполняется критерий смачивания, т.е. сумма поверхностной энергии пленки $\gamma_{f}$ 
и энергии границы раздела пленка/подложка $\gamma_{i}$ меньше, чем поверхностная энергия подложки $\gamma_{s}$ :

$$
\gamma_{f}+\gamma_{i}<\gamma_{s}
$$

В этом случае силы взаимодействия на границе раздела пленка/подложка предотвращают обнажение поверхности подложки. Если соотношение (2) не выполняется, т.е. пленка не смачивает подложку, то сплошной слой не формируется, а возникают лишь отдельные островки, распределенные по поверхности подложки (рис. $2, b$ ). Такой режим роста носит название механизма Фольмера-Вебера [57] и реализуется, в частности, при эпитаксии пленок соединений типа $\mathrm{A}^{\mathrm{III}} \mathrm{B}^{\mathrm{V}}$, например $\mathrm{GaAs}$, на подложках $\mathrm{Si}$ [58]. Наконец, возможен и третий механизм роста гетероэпитаксиальных пленок, когда сначала на поверхности подложки вырастает смачивающий слой толщиной в несколько монослоев, а затем начинается рост трехмерных островков (рис. 2,c). Подобный механизм формирования эпитаксиальных пленок называется режимом Странски-Крастанова [59] и в отличие от режима Фольмера-Вебера в данном случае пленка смачивает подложку. Однако сильные внутренние напряжения, возникающие при большом $(>2 \%)$ несоответствии решеток пленки и подложки, препятствуют поддержанию послойного роста. Данный механизм реализуется, в частности, при выращивании пленок $\mathrm{Ge}$ на подложках $\mathrm{Si}[60]$ и пленок InAs на подложках $\mathrm{GaAs}$ [61].

Моделирование гетероэпитаксиального роста в системах с сильным несоответствием решеток типа $\mathrm{CdTe} / \mathrm{GaAs}$ или $\mathrm{CdTe} / \mathrm{Si}$ показало, что упругая релаксация напряжений сопровождается образованием либо островков, либо $V$-образных дефектов [62]. Механизм огрубления поверхности пленок зависит от кинетического поведения атомов на поверхности растущего слоя, которое регулируется деформацией. На границах атомных кластеров происходит почти полная релаксация напряжений, в то время как в их центральной части энергия деформации существенно возрастает. Поэтому для релаксации напряжения атомы там должны перемещаться. Однако так как все соседние места заняты, релаксация возможна только путем межслойных миграций, что приводит к возникновению выступов на растущей поверхности. Поскольку в монокристаллических эпитаксиальных пленках отсутствуют внутренние границы раздела, основным механизмом массопереноса в них является диффузия по поверхности. Атомы перемещаются с одного места поверхности на другое, приводя к изменению свободной энергии, которая определяется градиентом химического потенциала вдоль поверхности. Таким образом, происходит перемещение центров роста вдоль поверхности в места с наименьшей свободной энергией, т. е. в вершины выступов, что и обусловливает переход к островковому механизму роста.

\section{2. Внутренние напряжения в поликристаллических пленках}

Одной из основных причин развития внутренних напряжений в поликристаллических пленках является эволюция и уплотнение их структуры в процессе роста. В отличие от эпитаксиальных, поликристаллические пленки, как правило, формируются в неравновесных условиях, обусловленных высокой скоростью нанесения и/или низкой температурой подложки. В таких условиях невысокая подвижность адатомов на поверхности подложки приводит к образованию большого числа зародышей и не позволяет обеспечить преимущественный рост кристаллитов с энергетически выгодной ориентацией. Поэтому поликристаллические пленки практически всегда формируются в соответствии с механизмом островкового роста Фольмера-Вебера, который включает в себя три последовательные стадии: зарождение и рост на подложке трехмерных островков (зародышей) осаждаемого материала, их последующую коалесценцию и затем рост сплошной пленки. При этом на разных стадиях роста пленок могут изменяться не только величина, но и знак внутренних напряжений. В островковых пленках, как правило, наблюдаются сжимающие напряжения [63]. Коалесценция островков, напротив, сопровождается развитием растягивающих напряжений [64]. Наконец, в сплошных пленках в зависимости от их материала и условий осаждения могут быть как сжимающие, так и растягивающие напряжения. Сжимающие напряжения обычно наблюдаются в сплошных пленках материалов, обладающих более высокой диффузионной подвижностью (низкой температурой плавления), таких как $\mathrm{Al}$, $\mathrm{Cu}, \mathrm{Ag}, \mathrm{Au}$ и др. [65-68]. В свою очередь, в пленках материалов, характеризующихся низкой диффузионной подвижностью (высокой температурой плавления), например, $\mathrm{Fe}, \mathrm{Cr}, \mathrm{Mo}, \mathrm{W}$ и др., как правило, развиваются растягивающие напряжения $[66,67,69]$. В то же время при определенных условиях осаждения может иметь место и обратная ситуация. Например, ионная бомбардировка пленок в процессе роста существенно повышает диффузионную подвижность адатомов, приводя к развитию сжимающих напряжений в пленках материалов с высокой температурой плавления [70]. Напротив, высокая скорость осаждения подавляет диффузионную подвижность адатомов, способствуя возникновению растягивающих напряжений в пленках материалов с низкой температурой плавления [71]. Ниже подробно рассмотрены основные механизмы эволюции напряжений в поликристаллических пленках на различных стадиях их формирования.

\subsection{1. Сжимающие напряжения в островковых пленках}

Даже на начальной стадии формирования, когда островки не соприкасаются друг с другом, в них развиваются сжимающие напряжения, величина которых 
может быть весьма высокой. Например, в островковых пленках Мо, нанесенных методом магнетронного распыления на подложку $\mathrm{Si}$, сжимающие напряжения достигали $\sim 1 \mathrm{GPa}[72]$. В островковых алмазных пленках на подложке из графита сжимающие напряжения превышали $2.3 \mathrm{GPa}[73]$.

Основным фактором, приводящим к возникновению сжимающих напряжений в островковых пленках, является сила поверхностного натяжения, стремящаяся минимизировать площадь поверхности островков, которые в результате приобретают выпуклую форму с положительной кривизной поверхности [63]. В соответствии с законом Лапласа это обусловливает возникновение внутри островка дополнительного капиллярного давления. Для островка сферической формы это дополнительное давление $\Delta P$ определяется как

$$
\Delta P=\frac{2 s}{R}
$$

где $s$ - сила поверхностного натяжения, а $R-$ радиус островка (в общем случае для островка произвольной формы вместо $R$ используется средний радиус кривизны его поверхности). Так как давление внутри выпуклого островка становится выше, равновесное межатомное расстояние там уменьшается по сравнению с аналогичным объемным материалом. Как видно из соотношения (3), увеличение размеров островка в процессе роста пленки должно приводить к снижению капиллярного давления и соответственно к постепенному увеличению постоянной решетки до ее объемного значения. Однако после достижения островком некоторого критического размера он закрепляется на подложке, что препятствует дальнейшему изменению внутри него межатомных расстояний в плоскости, параллельной границе раздела пленка/подложка $[74,75]$, поэтому продолжающийся рост островков способствует их деформации вдоль данной плоскости, которая в соответствии с законом Гука равна

$$
\varepsilon=-\frac{2 s\left(1-v_{f}\right)}{E_{f} R},
$$

где $E_{f}$ и $v_{f}$ - модуль упругости и коэффициент Пуассона пленки. Поскольку для большинства низкоиндексных поверхностей металлов и диэлектриков $s>0, \varepsilon<0$, то в островках развиваются сжимающие напряжения. Оценка внутренних напряжений, проведенная в соответствии с данным подходом, показала, что в островковых пленках $\mathrm{Au}$ на подложке $\mathrm{Al}_{2} \mathrm{O}_{3}$ их величина может достигать $2 \mathrm{GPa}$ [63], что согласуется с экспериментальными данными.

Также был предложен механизм, в соответствии с которым вклад в развитие сжимающих напряжений может вносить наличие адатомов или каких-либо дефектов на поверхности подложки и формирующихся островков [76,77]. Согласно данному механизму, взаимодействие адатома с поверхностью подложки приводит к формированию в ее поверхностном слое поля упругих деформаций, которое можно рассматривать как „силовой диполь“. Это поле обусловливает развитие сжимающих напряжений в островках, рост которых сопровождается непрерывным осаждением большого числа новых адатомов. В качестве подтверждения предложенного механизма авторы [77] указывают на то, что величина сжимающих напряжений в пленках падает с уменьшением потока адатомов. Прекращение процесса осаждения, т.е. поступления новых адатомов, приводит к резкому снижению величины сжимающих напряжений в островковых пленках. При этом некоторая доля напряжений остается нерелаксированной, поскольку их причиной является рассмотренное выше действие сил поверхностного натяжения. Однако детальные исследования, проведенные методом молекулярной динамики, показали, что напряжения, связанные с наличием поверхностных дефектов, существенно меньше, чем экспериментально измеренные сжимающие напряжения в островковых пленках [78].

\subsection{2. Растягивающие напряжения, вызванные коалесценцией островков}

По мере роста размеров островков они покрывают большую часть поверхности подложки, и соседние островки начинают взаимодействовать друг с другом. Результатом этого взаимодействия является коалесценция, т.е. слияние островков, которая сопровождается развитием в пленках растягивающих напряжений [79-85]. Максимальная величина данных напряжений $\sigma_{\max }$ существенно зависит от размера зерна при коалесценции $d_{0}$ $\left(\sigma_{\max } \sim 1 / d_{0}\right)$. В частности, при $d_{0} \leq 10 \mathrm{~nm}$ напряжения могут достигать нескольких GPa [86].

Движущей силой коалесценции является снижение полной энергии пленки при преобразовании двух свободных поверхностей островков в одну границу зерна. Изменение энергии в этом случае можно записать как

$$
\Delta \gamma=2 \gamma_{s}-\gamma_{g b}
$$

где $\gamma_{s}-$ поверхностная энергия, а $\gamma_{g b}-$ энергия границы зерна. Поскольку обычно $2 \gamma_{s}>\gamma_{g b}$, коалесценция островков является энергетически выгодной. Например, в случае большеугловых границ зерен, когда $\gamma_{g b}=(1 / 3) \gamma_{s}$ [87], образование границы зерна обеспечивает энергетический выигрыш $\Delta \gamma=(5 / 3) \gamma_{s}$.

На начальной стадии коалесценции рост островков и заполнение свободного пространства между ними осуществляется путем диффузии адатомов по поверхности островков и поверхности подложки. Однако когда расстояние между островками становится меньше некоторого критического значения, диффузионный механизм заполнения пустот оказывается затруднен. Было выдвинуто предположение, что заключительная стадия коалесценции (соответствующая толщине нанесенного слоя $10-50 \mathrm{~nm})$, во время которой островки становятся зернами сплошной пленки, и между ними формируются границы, сопровождается стягиванием пространства 


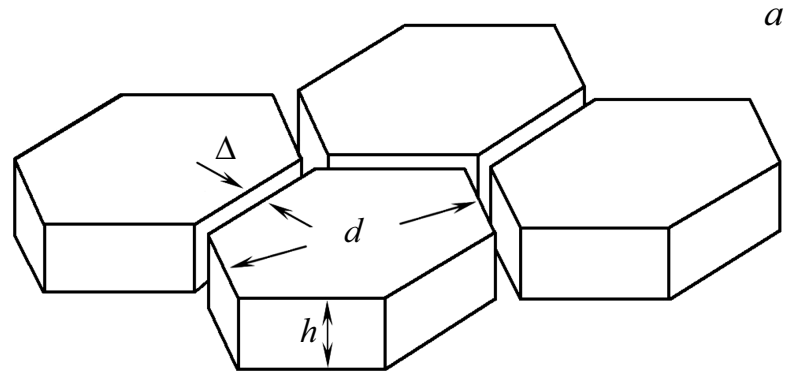

$b$

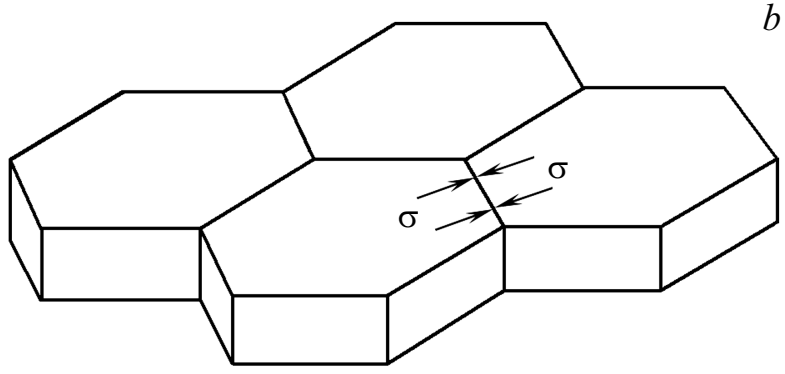

Рис. 3. Схематическое изображение поликристаллической тонкой пленки до $(a)$ и после $(b)$ коалесценции островков. Адаптировано из [64].

между боковыми гранями соседних островков посредством их спонтанной упругой деформации $[88,89]$.

Дальнейшее развитие модель, предложенная в $[88,89]$, получила в работе [64]. В ней рассматривается регулярный массив находящихся на подложке гексагональных островков высотой $h$ и поперечным размером $d$, которые до завершения процесса коалесценции расположены на расстоянии $\Delta$ друг от друга (рис. $3, a$ ). На этом этапе свободную энергию островковой пленки, приходящуюся на единицу ее площади, можно записать как [64]:

$$
W_{1}=W_{0}+\frac{4 h \gamma_{s}}{d}
$$

где $W_{0}$ - вклад в свободную энергию единицы площади пленки, обусловленный верхней гранью островка и границей раздела пленка/подложка, $\gamma_{s}$ - поверхностная энергия островков. Второй член в соотношении (6) выражает вклад в свободную энергию единицы площади пленки от боковых граней островков. Если пространство между островками стягивается посредством упругих смещений их боковых граней (рис. $3, b$ ), то каждый островок испытывает биаксиальную деформацию $\varepsilon=\Delta / d$. После завершения коалесценции свободная энергия единицы площади сплошной пленки равна

$$
W_{2}=W_{0}+\frac{2 h \gamma_{g b}}{d}+\frac{E_{f}}{\left(1-v_{f}\right)}\left(\frac{\Delta}{d}\right)^{2}
$$

где второй и третий члены представляют собой свободную энергию границ зерен и энергию деформации, приходящиеся на единицу площади пленки соответственно.

Соотношения (6) и (7) позволяют оценить максимальную ширину щели между островками, которая может быть стянута за счет их упругой деформации. Для этого нужно принять $W_{2}=W_{1}$, так как при $W_{2}>W_{1}$ стягивание щелей становится энергетически невыгодным. В результате из (6) и (7) следует, что

$$
\Delta_{\max }=\left[\frac{2 d\left(1-v_{f}\right)}{E_{f}}\left(2 \gamma_{s}-\gamma_{g b}\right)\right]^{1 / 2} .
$$

Соответственно максимальное растягивающее напряжение в пленке может достигать

$$
\begin{aligned}
\sigma_{\max } & =\frac{E_{f}}{\left(1-v_{f}\right)} \varepsilon_{\max }=\frac{E_{f}}{\left(1-v_{f}\right)} \frac{\Delta_{\max }}{d} \\
& =\left[\frac{2 E_{f}}{\left(1-v_{f}\right) d}\left(2 \gamma_{s}-\gamma_{g b}\right)\right]^{1 / 2} .
\end{aligned}
$$

Используя значения $E_{f}=100 \mathrm{GPa}, \quad d=10 \mathrm{~nm}$, $\gamma_{s}=1 \mathrm{~J} / \mathrm{m}^{2}$ и $\gamma_{g b}=0.5 \mathrm{~J} / \mathrm{m}^{2}$, получаем, что упругая деформация островков позволяет стянуть щели между островками шириной до $0.55 \mathrm{~nm}$, при этом максимальные растягивающие напряжения могут достигать $5.5 \mathrm{GPa}$. Полученное значение в несколько раз превышает экспериментальные значения напряжений в поликристаллических пленках, измеренные на стадии коалесценции островков [79-85]. Особенно велико это несоответствие для пленок с высокой диффузионной подвижностью адатомов (например, у пленок $\mathrm{Au}$, нанесенных при комнатной температуре). Очевидно, что данная модель является весьма упрощенной и содержит ряд не соответствующих действительности допущений. Например, она предполагает, что стенки островков расположены вертикально и могут взаимодействовать друг с другом через щель.

В [64] была также предложена более сложная и реалистичная с физической точки зрения модель. В ней заполнение щели между соседними островками и формирование границы зерна рассмотрены с позиций критерия разрушения Гриффитса как процесс закрытия трещины. Данная модель предполагает, что островки имеют округлую форму и их коалесценция начинается с возникновения контакта в одной точке. Далее зона между соседними островками рассматривается как трещина, закрытие которой является энергетически выгодным, так как позволяет понизить полную свободную энергию системы (см. соотношение (5)). В отличие от вышеописанной модели [89], в [64] предполагается, что процесс закрытия трещины происходит постепенно, сопровождаясь элементарными актами упругой деформации островков до тех пор, пока уменьшение поверхностной энергии за счет образования границы зерна превышает соответствующее увеличение энергии упругой деформации. Несмотря на существенные отличия данного механизма коалесценции островков от модели, предложенной в [89], полученное в [64] выражение для развивающихся в пленке средних растягивающих напряжений отличается 
от соотношения (9) только наличием множителя $1+v_{f}$ :

$$
\sigma_{a v}=\left[\frac{E_{f}}{\left(1-v_{f}\right)} \frac{2\left(1+v_{f}\right)}{d}\left(2 \gamma_{s}-\gamma_{g b}\right)\right]^{1 / 2} .
$$

Необходимо отметить, что средние напряжения, определяемые выражением (10), превышают максимальные напряжения в (9), т. е. оказываются еще более завышенными. Среди возможных причин, приводящих к подобному завышению, авторы [64] отмечают отсутствие учета в модели сдвиговых напряжений, возникающих на границе раздела пленка/подложка при деформации островков, а также заложенное в ней допущение о том, что коалесценция всех островков начинается одновременно.

Еще один подход к описанию механизма развития растягивающих напряжений в тонких пленках на стадии коалесценции островков был предложен в [90]. Авторы этой работы рассмотрели коалесценцию островков как контакт упругих тел, между которыми действует сила сцепления. Данная модель основана на классической теории Герца упругого контакта твердых тел с учетом когезионного взаимодействия между контактирующими поверхностями [91]. Для трехмерных островков полусферической формы в [90] получено следующее выражение для растягивающих напряжений, усредненных по объему островка:

$$
\sigma_{a v}=\frac{4\left(2 \gamma_{s}-\gamma_{g b}\right)}{d}
$$

Несколько неожиданным является тот факт, что в соответствии с данным походом величина напряжений не зависит от упругих свойств материала. Используя те же значения параметров, что и ранее $(d=10 \mathrm{~nm}$, $\gamma_{s}=1 \mathrm{~J} / \mathrm{m}^{2}$ и $\left.\gamma_{g b}=0.5 \mathrm{~J} / \mathrm{m}^{2}\right)$, получаем, что растягивающие напряжения в пленках могут достигать $600 \mathrm{MPa}$ Данное значение лучше согласуется с экспериментально полученными значениями напряжений. Тем не менее эта модель не позволяет объяснить большой разброс экспериментальных данных для различных пленок, так как величина, определяемая соотношением (11), по существу, может изменяться только за счет варьирования размеров островков.

\subsection{3. Механизмы развития растягивающих напряжений в сплошных пленках}

Как уже отмечалось выше, после завершения коалесценции островков и образования сплошной пленки, одним из основных факторов, определяющих величину внутренних напряжений в ней, является диффузионная подвижность адатомов, которая, в свою очередь, зависит от гомологической температуры (отношения температуры осаждения пленки к ее температуре плавления $\left.T_{d} / T_{m}\right)$ и скорости осаждения. В общем случае тонкопленочные материалы можно разделить на два типа [79-85,92,93]. Пленки первого типа, нанесенные при
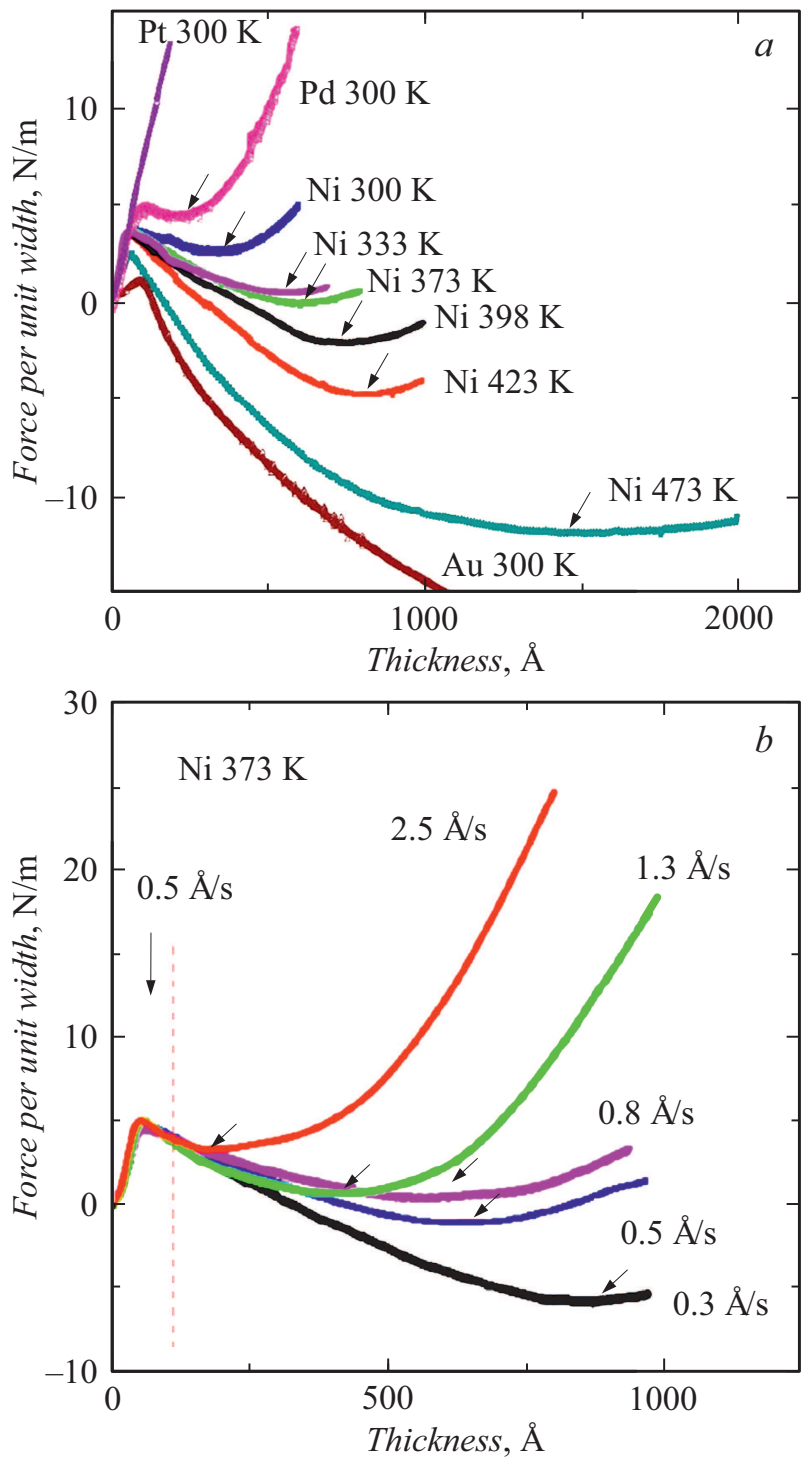

Рис. 4. Эволюция внутренних напряжений в пленках $\mathrm{Pt}, \mathrm{Pd}$, $\mathrm{Au}$ и $\mathrm{Ni}$, осажденных при различных температурах $(a)$, а также в пленках $\mathrm{Ni}$, нанесенных с разной скоростью осаждения $(b)$. Стрелками указана толщина пленок, при которой происходит смена характера изменения напряжений. Публикуется с разрешения Yu H.Z. и др. Acta Mater. 67, 189 (2014). Copyright 2014, Elsevier [85].

низкой гомологической температуре $\left(T_{d} / T_{m}<0.2\right.$, например, пленки $\mathrm{Fe}, \mathrm{Cr}$, Ti, Pt, осажденные при комнатной температуре) и/или высокой скорости, характеризуются низкой диффузионной подвижностью адатомов. В этих пленках растягивающие напряжения, возникающие на стадии коалесценции островков, сохраняются после ее завершения и возрастают с увеличением толщины нанесенного слоя (рис. 4). Пленки второго типа формируются при более высоких гомологических температурах и/или низкой скорости осаждения. У этих пленок с увеличением толщины происходит переход растягивающих внутренних напряжений в сжимающие, так что макси- 
мальная величина растягивающих напряжений соответствует завершению коалесценции островков (рис. 4). По данным [85] гомологическая температура пленок второго типа составляет порядка $0.22-0.24$ и выше. Так, $\mathrm{Au}, \mathrm{Ag}$ и $\mathrm{Cu}$ демонстрируют высокую подвижность адатомов уже при комнатной температуре, тогда как в случае пленок $\mathrm{Ni}$ для этого необходима температура осаждения выше $150^{\circ} \mathrm{C}$. В то же время авторы [84] получили пленки Тi, эволюция внутренних напряжений в которых характерна для пленок второго типа уже при гомологической температуре 0.15 . Возможным объяснением этого может быть различие в скоростях осаждения пленок.

В отличие от пленок первого типа величина растягивающих напряжений в которых не изменяется после завершения процесса нанесения, в пленках второго типа прекращение осаждения приводит к быстрой релаксации сжимающих напряжений (в течение нескольких минут после нанесения). При определенных условиях в них даже наблюдается обратный переход сжимающих напряжений в растягивающие [92]. При этом возобновление осаждения пленок вновь приводит к возникновению сжимающих напряжений [84]. Было обнаружено, что подобный характер изменения величины и знака внутренних напряжений может иметь место и до завершения процесса осаждения в случае нанесения пленок при определенных промежуточных температурах и скоростях осаждения. В частности, в пленках $\mathrm{Ni}$, нанесенных в диапазоне температур от 27 до $150^{\circ} \mathrm{C}$, после достижения некоторого максимального значения сжимающих напряжений начиналась их релаксация, которая при определенных значениях скорости осаждения заканчивалась повторным развитием растягивающих напряжений [85].

Эволюция внутренних напряжений в сплошных поликристаллических пленках является весьма сложным процессом, так как она контролируется не только конкуренцией между различными механизмами развития напряжений, но и их конкуренцией с одновременно действующими механизмами релаксации этих напряжений. При этом вклад этих механизмов в суммарную величину напряжений существенно зависит от материала пленок, а также метода и условий их осаждения. На сегодняшний день предложен целый ряд различных моделей, описывающих механизмы развития растягивающих напряжений в сплошных поликристаллических пленках. Ниже рассмотрены наиболее важные из них.

Увеличение растягивающих напряжений в пленках первого типа после завершения коалесценции островков обычно объясняется тем, что верхние слои пленки эпитаксиально растут на поверхности уже сформировавшихся зерен, наследуя их неравновесную структуру $[64,85,92,93]$. При этом во вновь осаждаемых слоях продолжается формирование границ зерен, зерна часто имеют столбчатую структуру, так что объем, приходящийся на границы зерен, линейно увеличивается с ростом толщины пленки. Поэтому растягивающие напряжения продолжают возрастать в соответствии с механизмом, описанным выше для стадии коалесценции островков.

Другой механизм развития растягивающих напряжений связан с рекристаллизацией и ростом зерен, протекающими в сплошной пленке как в процессе ее осаждения, так и после его окончания [81,86,92-94]. Этот механизм не играет значительной роли в пленках первого типа, поскольку в их случае низкая диффузионная подвижность адатомов не способствует существенному росту зерен, однако он вносит вклад в релаксацию сжимающих напряжений и повторное возникновение растягивающих напряжений в пленках второго типа, подвижность адатомов в которых высока.

Поскольку подложка не оказывает существенного ориентирующего действия на рост поликристаллических пленок, расположение и кристаллографическая ориентация соседних островков носят случайный характер, что не способствует формированию равновесных границ при их объединении. Неравновесный характер формирования поликристаллических пленок приводит к тому, что плотность материала на границах зерен оказывается ниже, чем внутри зерна. Границы зерен содержат избыточный свободный объем, который возникает как за счет увеличения среднего расстояния между атомами по сравнению с равновесным значением, так и вследствие формирования пор. Например, для ГЦК металлов избыточный свободный объем на единицу площади границы зерна составляет $\Delta V \sim 1 \AA$ [95]. В процессе роста зерен происходит уменьшение числа границ зерен и, следовательно, перераспределение этого свободного объема. В результате происходит уплотнение пленки, которое в свободном состоянии привело бы к уменьшению ее размеров. Однако так как пленка жестко связана с подложкой по границе раздела, она может изменить только свою толщину. Поперечные же размеры пленки остаются неизменными, и она испытывает биаксиальную деформацию, которая при увеличении среднего размера зерна от $d_{0}$ до $d$ составляет [86]:

$$
\varepsilon_{d}=\Delta V\left(\frac{1}{d}-\frac{1}{d_{0}}\right) .
$$

Если эта деформация аккомодируется упруго, то уплотнение пленки в процессе роста зерен обусловливает развитие в ней биаксиальных растягивающих напряжений

$$
\sigma=\frac{E_{f}}{\left(1-v_{f}\right)} \varepsilon_{d}
$$

и приводит к увеличению ее средней плотности энергии (энергии, приходящейся на единицу объема пленки) на величину

$$
\Delta F_{d}=\frac{E_{f}}{\left(1-v_{f}\right)} \varepsilon_{d}^{2} .
$$

Из вышеизложенного, в частности, следует, что растягивающие напряжения в пленках могут тормозить в них рост зерен, поскольку он оказывается энергетически 
невыгодным из-за дополнительного увеличения напряжений и роста упругой энергии. При достаточно малых $d_{0}$ $\left(d_{0} \leq 4 \mathrm{~nm}\right)$ снижение плотности энергии, связанное с уменьшением числа границ зерен на единицу площади пленки [86]:

$$
\Delta F_{g b}=\gamma_{g b}\left(\frac{2}{d_{0}}-\frac{2}{d}\right)
$$

может быть меньше, чем величина $\Delta F_{d}$. В этом случае каждому значению напряжений соответствует некоторый предельный размер зерна, при достижении которого рост зерен в пленке прекращается. Так, проведенные в [93] расчеты показали, что напряжения величиной $6 \mathrm{GPa}$ стабилизируют размер зерна в пленках металлов на уровне $1.3 \mathrm{~nm}$. Если же $\Delta F_{g b} \geq \Delta F_{d}$, то рост зерен будет продолжаться, приводя к развитию сильных деформаций. В общем случае наличие растягивающих напряжений способствует формированию мелкозернистых пленок, а сжимающие напряжения, напротив, благоприятствуют росту крупных зерен.

Следует отметить, что скорость увеличения напряжений, которые развиваются вследствие роста зерен, а также их итоговая величина существенно зависят от исходного размера зерна [94]. В случае очень мелких зерен $(\sim 1 \mathrm{~nm})$, которые, как правило, наблюдаются только у несплошных пленок, скорость роста напряжений наиболее высока, а сами напряжения при комнатной температуре могут достигать $1 \mathrm{GPa}$. В то же время для пленок с более крупными зернами $(\sim 20 \mathrm{~nm})$ скорость роста напряжений, вызванных ростом зерен, невелика, а их максимальная величина не превышает $1 \mathrm{MPa}$. Таким образом, как уже было отмечено выше, при низкой диффузионной подвижности адатомов рост зерен не может приводить к развитию сильных внутренних напряжений в сплошных пленках. Однако данный механизм развития напряжений становится весьма важным при высокой диффузионной подвижности адатомов, например, в случае осаждения пленок при повышенной температуре.

Даже в случае, когда зерна в пленке не растут, неравновесность границ зерен приводит к развитию релаксационных процессов. Чтобы понизить полную свободную энергию пленки, атомы на границах зерен стремятся занять равновесные позиции, что приводит к перераспределению избыточного свободного объема, т.е. уплотнению одних областей и возникновению пористости в других. Поскольку поверхностная энергия поры всегда больше, чем энергия границы зерна, в пленке возникает движущая сила, стремящаяся затянуть пору. Это обусловливает развитие упругих деформаций и растягивающих напряжений в пленках в соответствии с механизмом, аналогичным тому, который был описан выше для коалесценции островков [64,87-89]. Расчеты, проведенные в [94], показывают, что при малых размерах пор и высокой плотности их распределения по границам зерен развивающиеся там релаксационные процессы могут приводить к сильным растягивающим напряжениям (до $1 \mathrm{GPa}$ ) даже при комнатной температуре.

\subsection{4. Механизмы развития сжимающих напряжений в сплошных пленках}

В отличие от растягивающих напряжений, основным механизмом возникновения которых в поликристаллических пленках в настоящее время считается описанный выше процесс образования границ зерен, полное понимание механизмов развития в пленках сжимающих напряжений на сегодняшний день отсутствует. В ряде исследований предполагается, что сжимающие напряжения в сплошных пленках наследуются от островковых пленок, в которых, как отмечалось выше, они являются результатом действия капиллярных сил $[63,81,92,96]$. Авторы других работ [76,77] полагают, что, как и в островковых пленках, в процессе роста сплошных пленок действует механизм „силового диполя“, который обусловливает сжатие пленки вследствие взаимодействия адатомов с ее поверхностью. Также предполагается, что сжимающие напряжения в тонких пленках могут являться результатом внедрения избыточных атомов между соседними ступеньками на растущей поверхности [97]. Недавно предложенная модель подразумевает, что напряжения в сплошных поликристаллических пленках возникают в результате взаимодействия соседних зерен, которое обусловливает их деформацию, включая зернограничное проскальзывание $[98,99]$.

Особо следует отметить кинетическую модель, которая описывает эволюцию внутренних напряжений в пленках и покрытиях на основе динамических процессов, происходящих во время их роста на атомном уровне [100-104]. Данная модель связывает механизм развития сжимающих напряжений с диффузионным потоком атомов со свободной поверхности растущей пленки на границы зерен (рис. 5). Движущей силой этого потока является градиент химического потенциала, возникающий вследствие неравновесности процесса осаждения и повышенной концентрации адатомов на поверхности пленки. Направленный диффузионный поток приводит к избыточному внедрению атомов на границах зерен, т.е. к уплотнению пленки и развитию сжимающих напряжений. На стадии стабильного роста сплошной пленки, когда длина границ зерен растет с той же скоростью, что и толщина пленки, среднее напряжение в последней, согласно кинетической модели, можно записать как [103]

$$
\sigma_{f}=\sigma_{c}+\left(\sigma_{t}-\sigma_{c}\right) \exp \left(-\beta D / R_{d} d\right)
$$

где $\sigma_{c}-$ сжимающее напряжение, обусловленное внедрением атомов на границы зерен, $\sigma_{t}$ - растягивающее напряжение, вызванное образованием новых участков границ зерен, $\beta$ - параметр, зависящий от концентрации на поверхности пленки подвижных адатомов, атомного объема и модуля упругости материала пленки, а также температуры, $D$ - эффективный коэффициент диффузии адатомов, $R_{d}$ - скорость осаждения пленки, $d$ - размер зерна. Проведенные оценки показали, что для развития напряжений и деформаций, которые 


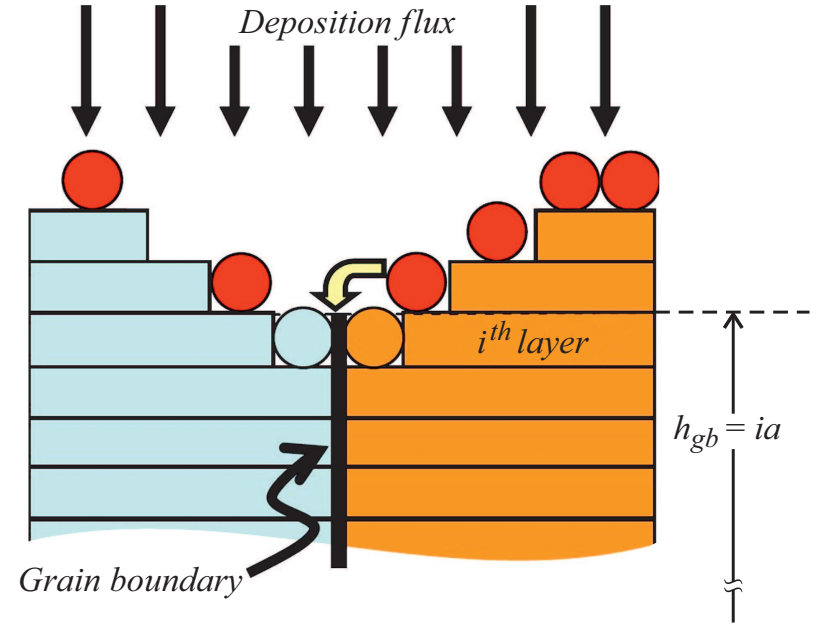

Рис. 5. Схема, иллюстрирующая механизм развития сжимающих напряжений в поликристаллической тонкой пленке за счет диффузии атомов с ее поверхности на границы зерен. Публикуется с разрешения Chason E. Thin Solid Films 516, 1 (2012). Copyright 2012, Elsevier [102].

обычно наблюдаются во время роста пленок материалов с высокой подвижностью адатомов (деформация около $0.1 \%$ ), необходим рост химического потенциала на свободной поверхности $0.15 \mathrm{kT}$ [100]. Это приблизительно соответствует внедрению одного избыточного атома на границе зерна за время роста одного монослоя пленки.

Достоинством кинетической модели является тот факт, что она рассматривает в качестве основной причины развития сжимающих напряжений в поликристаллических пленках их неравновесный характер и напрямую связывает величину напряжений с параметрами осаждения и микроструктуры пленок (см. соотношение (16)). Поэтому она позволяет легко объяснить наблюдающуюся в экспериментах зависимость величины внутренних напряжений от температуры и скорости осаждения пленок. При низкой температуре (или высокой скорости осаждения) диффузионная подвижность адатомов очень мала и они закрепляются на свободной поверхности пленки. В результате из (16) следует, что $\sigma_{f} \approx \sigma_{t}$, т.е. в пленке действуют только механизмы генерации растягивающих напряжений, преимущественно обусловленные образованием границ зерен. Напротив, при высокой температуре (или низкой скорости осаждения) поверхностная диффузия и диффузия по границам зерен могут обеспечить контролируемый градиентом химического потенциала массоперенос со свободной поверхности на границы зерен, приводя к развитию сжимающих напряжений. Поскольку сжимающие напряжения действуют в плоскости пленки, они постепенно приводят к повышению химического потенциала на границах зерен. Этот процесс продолжается до тех пор, пока химический потенциал на границах зерен не станет равным химическому потенциалу на поверхности пленки, т. е. пока не установится квазиравновесное состояние. После этого сжимающие напряжения больше не растут, и одновременно действующие механизмы развития растягивающих напряжений обусловливают релаксацию сжатия. Именно эта картина наблюдается в пленках, нанесенных при промежуточных гомологических температурах и скоростях осаждения, в которых сжимающие напряжения после достижения определенной толщины пленки начинают релаксировать (рис. 4).

Еще одно преимущество данной модели заключается в том, что она позволяет объяснить наблюдающуюся в экспериментах релаксацию сжимающих напряжений в пленках после прекращения процесса их нанесения [65,105-107]. Как только поток атомов, осаждаемых на свободную поверхность пленки, становится равным нулю, химический потенциал там снижается до равновесного значения. В то же время химический потенциал на границах зерен остается повышенным из-за накопления избыточных атомов. В результате возникает противоположно направленный градиент химического потенциала, который вызывает обратный поток атомов с границ зерен на свободную поверхность, приводящий к релаксации сжимающих напряжений. Возобновление осаждения пленок вновь вызывает рост химического потенциала на свободной поверхности пленки и поток атомов на границы зерен.

Недавно кинетическая модель получила дальнейшее развитие так, чтобы учесть влияние роста зерен в процессе осаждения поликристаллических пленок на эволюцию в них внутренних напряжений [108]. При этом рассматривались два эффекта: развитие в пленке напряжений, обусловленных изменением микроструктуры уже сформировавшихся слоев, и влияние увеличения исходных размеров зерен во вновь осаждаемых слоях на величину напряжений в них. Проведенные расчеты показали хорошее согласие с данными экспериментальных исследований, согласно которым величина сжимающих напряжений в пленках, характеризующихся существенным ростом размеров зерен в процессе осаждения, непрерывно изменяется с увеличением толщины нанесенного слоя [85]. Анализ полученных данных свидетельствует о том, что основной причиной изменения величины напряжений в подобных пленках является не эволюция микроструктуры сформировавшихся слоев, а увеличение поперечного размера зерен в новых слоях пленки с ростом ее толщины. Последнее приводит к постепенному уменышению длины границ зерен, приходящейся на единицу площади поверхности пленки, что способствует снижению количества адатомов, внедряющихся на границы зерен, и, как следствие, уменьшению сжимающих напряжений.

Кинетическая модель продемонстрировала хорошее согласие с эволюцией внутренних напряжений в пленках $\mathrm{Ni}$ [109-111] и $\mathrm{Cu}$ [111-113], полученных методом электролитического осаждения. В частности, в 
данных исследованиях наблюдалось уменьшение величины напряжений с увеличением скорости осаждения и размера зерен, что прямо следует из кинетической модели. При этом следует отметить, что осаждение данных пленок протекало при низкой гомологической температуре, когда диффузионные процессы в тонких пленках в значительной степени подавлены. В [65] было показано, что степень релаксации сжимающих напряжений в пленках $\mathrm{Au}$ после прекращения их нанесения методом химического осаждения из паровой фазы уменьшается с ростом среднего размера зерна. Этот результат также хорошо согласуется с кинетической моделью, поскольку больший размер зерен соответствует меньшей длине границ зерен, приходящейся на единицу площади поверхности пленки. Следовательно, увеличение размера зерен обусловливает снижение числа атомов, которые могут диффундировать из границ зерен на свободную поверхность пленки, приводя к релаксации сжимающих напряжений. К сожалению, в работе [65] не приведена зависимость величины развивающихся сжимающих напряжений от размера зерна, что не позволяет сравнить влияние границ зерен на развитие и релаксацию напряжений. Недавний анализ результатов измерения напряжений в пленках $\mathrm{Ni}$, полученных методом электронно-лучевого испарения [85], проведенный с помощью модифицированной кинетической модели, учитывающей рост зерен в процессе осаждения пленок, показал, что она способна адекватно описать эволюцию напряжений в случае пленок, осажденных при высоких гомологических температурах, когда имеет место высокая подвижность адатомов [108]. В частности, она позволила объяснить зависимость напряжений в данных пленках от температуры и скорости их осаждения.

В то же время в [77] было выявлено существенное различие между скоростями релаксации сжимающих напряжений при прекращении роста пленок $\mathrm{Cu}$ и их повторного развития после возобновления процесса осаждения. Восстановление сжимающих напряжений происходило на 1-2 порядка быстрее, чем их релаксация, что не вполне согласуется с кинетической моделью, в которой потоки атомов, направленные к границам зерен и от них, предполагаются симметричными. С другой стороны, наблюдающееся различие может быть следствием разницы между энергиями вновь осаждаемых адатомов и атомов, диффундирующих из границ зерен, которая существенно влияет на их диффузионную подвижность. Исследование эволюции внутренних напряжений в тонких пленках $\mathrm{Fe}$, нанесенных методом электронно-лучевого испарения, не выявило существенного влияния размера зерен на величину внутренних напряжений [114]. При этом степень релаксации сжимающих напряжений после прекращения осаждения пленок возрастала с увеличением их толщины. Подобные эффекты противоречат не только кинетической модели, но и механизму развития сжимающих напряжений в результате взаимодействия адатомов с поверхностью роста [76,77]. Авторы [114] полагают, что обратимая релаксация напряжений в тонких плен- ках $\mathrm{Fe}$ после прекращения их осаждения обусловлена перестройкой поверхности, которая контролируется поверхностной диффузией. После прекращения процесса осаждения атомы диффундируют из более напряженной центральной части зерна к его границам, что приводит к релаксации напряжений и сглаживанию поверхности. Возобновление роста вызывает обратный процесс огрубления поверхности и повторного развития сжимающих напряжений.

Таким образом, несмотря на большое число экспериментальных и теоретических исследований, а также многочисленные обзоры современных представлений о причинах и механизмах развития внутренних напряжений в тонких поликристаллических пленках в процессе роста $[67,69,75,92,94,97,102,115-119]$, на сегодняшний день ни одна из предложенных моделей не способна полностью объяснить все экспериментально наблюдаемые закономерности их эволюции. Очевидно, что для понимания и учета всех механизмов возникновения и эволюции внутренних напряжений в поликристаллических пленках требуются дальнейшие экспериментальные и теоретические исследования. При этом одним из наиболее перспективных направлений данных исследований является дальнейшее развитие и валидация кинетической модели, которая объединяет в себе механизмы развития растягивающих напряжений из-за образования границ зерен [64] и сжимающих напряжений, обусловленных внедрением на границах зерен избыточных атомов [100].

\section{3. Внутренние напряжения, обусловленные образованием дефектов в пленках}

Существенный вклад в развитие внутренних напряжений в тонких пленках и покрытиях, особенно полученных методами распыления (sputtering) или ионного напыления (ion-assisted deposition), основанными на осаждении частиц, обладающих высокой кинетической энергией, вносят дефекты (межузельные атомы, вакансии, дислокации и др.), образующиеся в пленках в процессе осаждения. С учетом одновременного действия других механизмов развития напряжений, напряжения, обусловленные дефектами, могут достигать очень высоких значений. Например, в пленках $\mathrm{TiN}$, нанесенных методом магнетронного распыления импульсами высокой мощности (high-power impulse magnetron sputtering), величина остаточных сжимающих напряжений превышала $10 \mathrm{GPa}[120,121]$.

Одним из важных механизмов развития напряжений в пленках, нанесенных методами, использующими высокоэнергетические частицы, является так называемый „атомный (ионный) наклеп“ (atomic или ion peening) [122-124]. При соударении с растущей пленкой часть адатомов может внедряться в ее поверхностный слой, в междоузлия кристаллической решетки. Это приводит к дисторсии кристаллической решетки и избыточному уплотнению пленки. Как следствие, в ней возни- 
кают сжимающие напряжения, величина которых прямо пропорциональна молярному объему и модулю упругости пленки [125]. Наряду с атомами распыляемого материала, в междоузлия кристаллической решетки могут внедряться и примесные атомы, и ионы, например, ионы инертного газа, использующиеся для бомбардировки мишени. „Атомный наклеп“ преимущественно имеет место при низких гомологических температурах, когда низкая диффузионная подвижность адатомов не позволяет им переместиться в равновесные положения [69]. При высокой гомологической температуре внедрившиеся атомы легко диффундируют на свободную поверхность, либо на границы зерен, вследствие чего данный механизм не оказывает существенного влияния на развитие напряжений в пленках. Еще одним важным параметром, влияющим на концентрацию межузельных атомов и, тем самым, на величину внутренних напряжений в пленках, полученных методом распыления, является давление в рабочей камере $[69,126]$. В условиях низкого давления большинство осаждаемых атомов не испытывают столкновений между собой и при соударении с поверхностью пленки обладают высокой энергией, которая способствует их внедрению в междоузлия и развитию сжимающих напряжений. Напротив, при высоком давлении атомы многократно сталкиваются друг с другом и с ионами рабочего газа, что приводит к потерям энергии и малой концентрации точечных дефектов, в результате чего в пленках могут возникать остаточные растягивающие напряжения [126].

Существенное влияние на развитие сжимающих напряжений в пленках вследствие „атомного наклепа“ оказывает напряжение смещения, приложенное к подложке [115,127]. При высоких напряжениях смещения вблизи поверхности подложки создается сильное электромагнитное поле, которое ускоряет бомбардирующие ее ионы. Это приводит к увеличению их кинетической энергии и, как следствие, повышает концентрацию точечных дефектов в пленке. Так, в пленках $\mathrm{Cr}$, напыленных при напряжении смещения до $55 \mathrm{~V}$, развивались растягивающие напряжения [128]. В то же время повышение напряжения смещения до $75 \mathrm{~V}$ и более приводило к возникновению в них сжимающих напряжений 0.5-1 GPa, которые были следствием „атомного наклепа“.

Высокоэнергетические атомы и ионы могут приводить к появлению в пленках не только межузельных атомов, но и атомов замещения [115]. Этот тип точечных дефектов образуется, например, при напылении композиционных пленок. При этом, если замещение происходит атомом, имеющим больший радиус, чем атом решетки, то в пленке развиваются сжимающие напряжения. В противном случае возникают растягивающие напряжения. Величина данных напряжений может достигать очень высоких значений. Так, было показано, что замещение 1 wt.\% атомов азота атомами титана в пленках TiN приводит к развитию сжимающих напряжений, величина которых достигает 4.1 GPa [129].
Глубина возникновения точечных дефектов сильно зависит от энергии бомбардирующих частиц. Моделирование методами молекулярной динамики показало, что при бомбардировке медной подложки атомами $\mathrm{Cu}$ для появления межузельных атомов необходима энергия $20 \mathrm{eV}$ [130]. При этом данные атомы проникают во второй сверху слой подложки. Увеличение энергии падающих атомов до $80 \mathrm{eV}$ позволило им проникать в третий сверху слой подложки, при этом глубина, на которой возникли межузельные атомы, достигла 12 монослоев. В этом случае смещения атомов развивались путем цепочки фокусированных замещающих столкновений.

Модели, предложенные для описания механизмов развития напряжений при внедрении атомов и ионов, рассматривают напыленную пленку, как матрицу, содержащую внедренные частицы. В этом случае напряженнодеформированное состояние пленки представляет собой комбинацию гидростатических напряжений, обусловленных непосредственно образованием дефекта, и биаксиальных напряжений, вызванных ограничениями на изменение размеров, накладываемых подложкой на пленку [129,131-133]. При этом гидростатические и биаксиальные напряжения имеют противоположный знак, т.е. гидростатическое расширение пленки, обусловленное внедрением точечного дефекта, вызывает биаксиальное сжатие в плоскости пленки.

Недавно для описания эволюции напряжений в пленках, полученных с использованием высокоэнергетических частиц, была предложена расширенная кинетическая модель [134]. Наряду с термически активируемыми диффузионными процессами на поверхности и границах зерен, описываемыми в кинетической модели для низкоэнергетических методов осаждения (см. предыдущий раздел), расширенная кинетическая модель также учитывает роль в развитии внутренних напряжений точечных дефектов, образующихся в пленках в результате „атомного наклепа“. Согласно данному подходу, среднее напряжение в пленке может быть записано в виде суммы трех слагаемых

$$
\sigma_{f}=\sigma_{g r}+\sigma_{g b}+\sigma_{b},
$$

где $\sigma_{g r}-$ напряжение, развивающееся в процессе роста пленки, которое определяется соотношением (16), $\sigma_{g b}$ - напряжение, обусловленное уплотнением пленки из-за внедрения дефектов (атомов) в области, прилегающие к границам зерен, а $\sigma_{b}$ - напряжение, связанное с внедрением дефектов в объем зерен. Второе и третье слагаемые в (17) определяются как [134]

$$
\sigma_{g b}=A(l / d)
$$

и

$$
\sigma_{b}=(1-l / d) \sigma_{0} C_{s s},
$$

где $A$ - параметр, зависящий от энергии и потока бомбардирующих частиц, а также от скорости роста пленки, $l$ - глубина внедрения дефекта в пленку, $d-$ 
размер зерен, $\sigma_{0}$ - напряжение, создаваемое в пленке одним дефектом, $C_{s s}-$ средняя концентрация дефектов в пленке на стадии установившегося роста.

Поскольку в модели рассматриваются только дефекты, образовавшиеся в результате внедрения в пленку избыточных атомов, два последних слагаемых в (17) представляют собой сжимающие напряжения. Их сумма может превышать напряжения $\sigma_{g r}$, обусловленные термически активируемыми диффузионными процессами в растущей пленке, так что суммарное напряжение $\sigma_{f}$ также будет сжимающим $[118,134]$. Это позволяет объяснить, почему в условиях бомбардировки высокоэнергетическими частицами даже в пленках материалов с низкой диффузионной подвижностью атомов часто развиваются сжимающие напряжения [129,135,136]. Расширенная кинетическая модель продемонстрировала хорошее согласие с экспериментальными измерениями внутренних напряжений в пленках Та [118], Мо [134] и $\mathrm{Cu}$ [137], полученных методом магнетронного распыления. В частности, из нее следует, что чем быстрее растет пленка, тем больше дефектов в нее внедряется, что объясняет наблюдающееся увеличение сжимающих напряжений с повышением скорости осаждения пленок. Также модель позволила предсказать наблюдающийся в экспериментах рост сжимающих напряжений с уменьшением размера зерен в пленках. Тем не менее пока описание эволюции внутренних напряжений в тонких пленках на основе кинетической модели проведено для очень небольшого числа материалов и условий осаждения. Поэтому для ее верификации и дальнейшего развития требуются интенсивные исследования.

Другой тип точечных дефектов - вакансии - также может являться источником возникновения внутренних напряжений в тонких пленках. Поскольку пленки и покрытия осаждаются в высоконеравновесных условиях, обычно они содержат большое число вакансий. Релаксационные процессы, протекающие как в процессе осаждения пленок, так и после его окончания, приводят к упорядочению их структуры, в частности, к аннигиляции вакансий. Данный процесс может развиваться как в поликристаллических, так и в монокристаллических, а также в аморфных пленках. Он приводит к развитию внутренних напряжений, знак и величина которых зависят от парциального молярного объема вакансий, а также от расположения места аннигиляции [94]. Например, в поликристаллических пленках аннигиляция вакансии на границе зерна, расположенной перпендикулярно плоскости пленки, обусловливает возникновение растягивающих напряжений. Однако аннигиляция вакансии внутри зерна может, напротив, вызывать увеличение объема пленки, если объем вакансии меньше объема атома. Следствием этого будет развитие сжимающих напряжений. Следует отметить, что при низких температурах отжига напряжения, вызываемые аннигиляцией вакансий, невелики. Так, проведенные в [94] оценки показали, что напряжения, обусловленные аннигиляцией вакансий в пленках $\mathrm{Ni}$, подвергнутых отжигу в течение $1 \mathrm{~h}$ при температуре $227^{\circ} \mathrm{C}$, не превышают нескольких десятков МРа. При еще более низких температурах маловероятно, чтобы данный механизм вносил существенный вклад в развитие напряжений в тонких пленках.

На практике в пленках и покрытиях одновременно присутствуют различные типы точечных дефектов. Поэтому их влияние на развитие внутренних напряжений носит сложный характер, так как различные типы дефектов не только обусловливают разные механизмы возникновения напряжений, но и взаимодействуют между собой, что также может изменять напряженнодеформированное состояние материала. Моделирование, проведенное в [138], показало, что дефекты, возникающие в пленках, могут представлять собой дефект Френкеля, т.е. пару межузельный атом-вакансия. Более позднее моделирование методом молекулярной динамики выявило, что сжимающие напряжения в пленках, подвергнутых бомбардировке высокоэнергетическими ионами, могут развиваться в результате конкурирующих механизмов генерации и рекомбинации пар Френкеля [139].

\section{4. Внутренние напряжения, вызванные внедрением примесей и фазовыми превращениями в системе пленка/подложка}

Внутренние напряжения в пленках и покрытиях также могут возникать вследствие фазовых превращений, происходящих внутри них в процессе осаждения, образования новых фаз и преципитатов, легирования дополнительными элементами, а также внедрения примесей. Так, известно, что трансформация аморфной фазы в кристаллическую приводит к увеличению плотности материала [140]. Из-за жесткой связи с подложкой уплотнение пленок может происходить только посредством уменьшения их толщины, которое у некоторых материалов с изменяемым фазовым состоянием (phase change materials) является весьма существенным. Например, при кристаллизации пленок халькогенидов (GeTe, $\mathrm{Ge}_{4} \mathrm{Sb}_{1} \mathrm{Te}_{5}$ и др.) их толщина уменьшается на 8-9\% [141,142]. Подобная трансформация вызывает развитие аналогичных по величине деформаций и, следовательно, растягивающих напряжений порядка $1 \mathrm{GPa}$ и более в плоскости пленки. Изменение фазового состояния пленок может происходить как вследствие различных внешних воздействий, например, в результате термического отжига [143] и лазерного облучения [144], так и непосредственно в процессе роста. Подобный эффект, в частности, наблюдался при выращивании пленок Sb [145]. Первоначально данные пленки росли в аморфном состоянии, однако после достижения некоторой критической толщины произошла их кристаллизация, которая сопровождалась развитием сильных напряжений.

Другой тип фазовых превращений, происходящих в процессе осаждения пленок и покрытий, связан с 
протеканием в них химических реакций, приводящих к образованию новых фаз. Это могут быть реакции, обусловленные взаимной диффузией атомов пленки и подложки, либо диффузией между различными слоями в многослойных структурах. Кроме того, возможны химические реакции атомов пленки с молекулами остаточных газов, либо с внедренными примесными атомами.

Одним из наиболее характерных примеров реакций между химическими элементами пленки и подложки является образование силицидов металлов при нанесении металлических пленок на кремниевую подложку. При этом величину и знак напряжений, возникающих при образовании новой фазы, нельзя однозначно определить путем вычисления разницы между объемами исходных и новой фаз. В общем случае, вследствие малого атомного объема кремния, образование силицидов в тонких пленках металлов всегда сопровождается уплотнением материала, т.е. данный процесс должен приводить к развитию растягивающих напряжений. Тем не менее исследования свидетельствуют о том, что формирование $\mathrm{Ni}_{2} \mathrm{Si}$ [146], $\mathrm{Pt}_{2} \mathrm{Si}$ [147], $\mathrm{Pd}_{2} \mathrm{Si}$ [148] и др. часто приводит к возникновению в пленках сжимающих напряжений, которые могут достигать $1.5 \mathrm{GPa}$. Причина этого заключается в меньшей диффузионной подвижности атомов кремния по сравнению с атомами металла. Поэтому после формирования тонкого силицидного слоя между пленкой и подложкой химические реакции протекают преимущественно в верхнем слое подложки, прилегающем к границе раздела с пленкой [149]. Следовательно, для оценки возникающих деформаций и напряжений необходимо рассматривать изменения объема только этой фазы, т.е. сравнивать объем кремния с объемом силицида. Поскольку в этом случае объем новой фазы оказывается больше, в слое силицида развиваются сжимающие напряжения. Исследования показывают, что возникновение напряжений в металлических пленках, осажденных на подложку $\mathrm{Si}$, может быть связано не столько с самим формированием силицидного слоя, сколько с его трансформацией из аморфного состояния в кристаллическое $[150,151]$. Поскольку, как отмечалось выше, при этом происходит существенное уплотнение материала, то в пленках развиваются растягивающие напряжения.

Другим примером возникновения напряжений в тонких пленках в результате химической реакции является взаимодействие $\mathrm{Ti}$ и $\mathrm{Al}$ с образованием преципитатов $\mathrm{TiAl}_{3}$. Данное явление наблюдалось, в частности, при выращивании многослойных пленок Ti/Al [152]. Поскольку в этом случае образование новой фазы сопровождается существенным уменьшением объема, в пленках развивались сильные растягивающие напряжения, которые могут приводить к образованию пор.

Величина и знак напряжений, возникающих в результате образования новых фаз, определяются химическим составом пленок и условиями их осаждения. Так, диффузия кислорода в пленки $\mathrm{Al}$ из нижележащих слоев

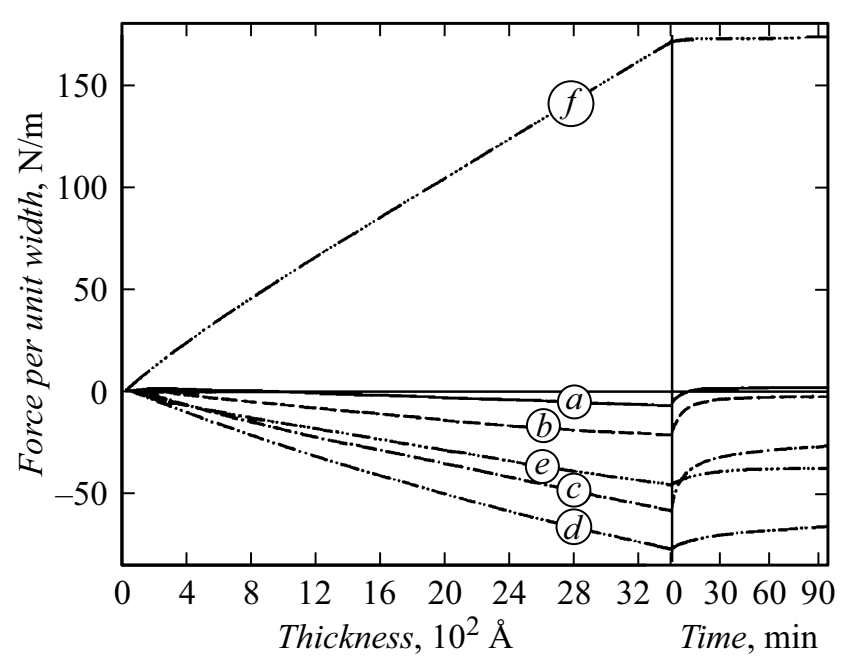

Рис. 6. Влияние парциального давления кислорода на внутренние напряжения в пленках Al. Пленки осаждались при парциальном давлении кислорода $\sim 1 \cdot 10^{-9}(a), 6 \cdot 10^{-6}(b)$, $6 \cdot 10^{-5}(c), 6 \cdot 10^{-4}(d), 1 \cdot 10^{-3}(e)$ и $3 \cdot 10^{-3} \mathrm{~Pa}(f)$. Публикуется с разрешения Abermann R. Thin Solid Films 186, 233 (1990). Copyright 1990, Elsevier [80].

приводила к развитию в них растягивающих напряжений [80]. В то же время диффузия кислорода из слоев $\mathrm{YBa}_{2} \mathrm{Cu}_{3} \mathrm{O}_{7-x}$ в слои $\mathrm{Ag}$ и $\mathrm{Au}$ обусловливала возникновение в последних сжимающих напряжений [153].

Результат взаимодействия пленки с остаточными газами в рабочей камере сложным образом зависит от их парциального давления. Так, при повышении парциального давления кислорода при осаждении пленок $\mathrm{Al}$ с $8 \cdot 10^{-7}$ до $6 \cdot 10^{-4} \mathrm{~Pa}$ в них наблюдался постепенный рост величины сжимающих напряжений (рис. 6) [80]. Однако дальнейшее повышение парциального давления кислорода приводило сначала к снижению сжимающих напряжений, а при давлении $3 \cdot 10^{-3} \mathrm{~Pa}-$ к развитию растягивающих напряжений в пленках Al. Данное поведение величины внутренних напряжений объясняется в [80] тем, что при малом парциальном давлении кислорода он поглощается в приповерхностном слое растущей пленки в виде атомов внедрения. Это приводит к уплотнению пленок и возникновению в них сжимающих напряжений. При достижении давления $6 \cdot 10^{-4} \mathrm{~Pa}$ приповерхностный слой растущей пленки оказывается полностью насыщен кислородом. Поэтому в пленке образуются преципитаты оксида алюминия, которые тормозят поверхностную диффузию атомов $\mathrm{Al}$ и способствуют уменьшению размера зерен. Последнее, в свою очередь, вызывает увеличение относительного объема образующихся границ зерен и, как следствие, рост растягивающих напряжений, возникающих при их формировании. В результате происходит частичная релаксация сжимающих напряжений. При давлении кислорода $3 \cdot 10^{-3} \mathrm{~Pa}$ на поверхности пленки $\mathrm{Al}$ формируется сплошной слой оксида алюминия, и напряжения в ней становятся растягивающими. 


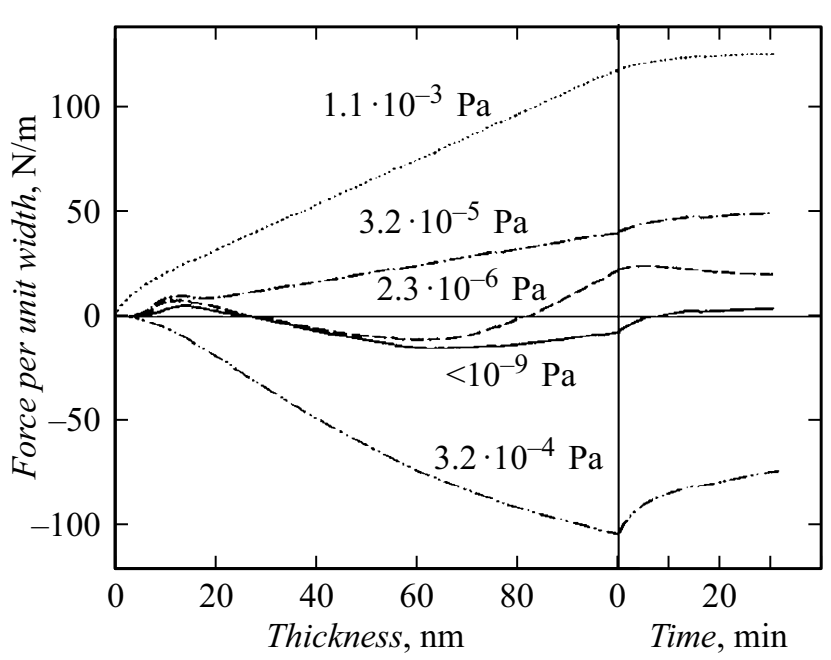

Рис. 7. Влияние парциального давления кислорода на внутренние напряжения в пленках Cr. Публикуется с разрешения Thurner G. и др. Vacuum 41, 1300 (1990). Copyright 1990, Elsevier [154].

Еще более сложная зависимость величины внутренних напряжений от парциального давления кислорода наблюдалась при нанесении пленок $\mathrm{Cr}$ (рис. 7) [154]. Так как осаждение пленок проводили при повышенной температуре $\left(300^{\circ} \mathrm{C}\right)$, при малом парциальном давлении кислорода $\left(\leq 2.3 \cdot 10^{-6} \mathrm{~Pa}\right)$ наблюдалась эволюция напряжений, характерная для пленок с высокой диффузионной подвижностью атомов. Сначала в них возникали растягивающие напряжения, которые затем переходили в сжимающие, а при определенной толщине вновь становились растягивающими. При повышении парциального давления кислорода до $3.2 \cdot 10^{-5}$ Ра независимо от толщины пленок $\mathrm{Cr}$ в них всегда присутствовали только растягивающие напряжения. При давлении $3.2 \cdot 10^{-4} \mathrm{~Pa}$, напротив, напряжения всегда были сжимающими. Наконец, при парциальном давлении кислорода $1.1 \cdot 10^{-3} \mathrm{~Pa}$ в пленках вновь развивались только растягивающие напряжения, величина которых была существенно выше, чем при давлении $3.2 \cdot 10^{-5} \mathrm{~Pa}$. Предложенное авторами [154] объяснение наблюдаемой зависимости внутренних напряжений от парциального давления кислорода во многом совпадает с вышеописанной моделью для пленок Al [80]. Однако в данном случае предполагается, что при малом парциальном давлении кислорода его основное действие связано с подавлением диффузионной подвижности адатомов. В результате имеет место уменьшение размера зерен в пленке, рост относительного объема границ зерен и, как следствие, развитие растягивающих напряжений. При повышении давления атомы кислорода внедряются в междоузлия кристаллической решетки поверхностного слоя $\mathrm{Cr}$, что приводит к развитию сжимающих напряжений. Наконец, при давлении $1.1 \cdot 10^{-3} \mathrm{~Pa}$ на поверхности пленки $\mathrm{Cr}$ формируется сплошной слой оксида хрома, что приводит к развитию сильных растягивающих напряжений.

Необходимо отметить, что на сегодняшний день отсутствует полное понимание факторов, контролирующих эволюцию внутренних напряжений в тонких пленках при изменении параметров осаждения. Тем не менее имеющиеся данные свидетельствуют о том, что внедрение примесей и фазовые превращения в тонких пленках сопровождаются развитием конкурирующих механизмов развития внутренних напряжений. Вклад каждого из этих механизмов в суммарную величину напряжений существенно зависит от условий роста пленок. Поэтому для получения пленок с требуемым уровнем напряжений необходимо проводить исследования в широком диапазоне параметров их осаждения.

\section{2. Напряжения, развивающиеся в тонкопленочных структурах при внешних воздействиях}

\section{1. Термические напряжения}

Важный вклад в общий уровень напряжений в тонких пленках и покрытиях вносят термические напряжения. Термические напряжения являются внешними, поскольку они вызваны изменениями температуры, происходящими, как правило, после окончания процесса осаждения пленок. Тем не менее данные напряжения могут быть связаны непосредственно с процессом осаждения пленок, поскольку многие технологии их выращивания, например, химическое осаждение из паровой фазы, термическое окисление и др., требуют нанесения пленок и покрытий при высоких температурах (до $1000^{\circ} \mathrm{C}$ и выше) $[155,156]$. Кроме того, термические напряжения могут развиваться при термической обработке пленок после их нанесения, а также вследствие изменений температуры в процессе эксплуатации тонких пленок и покрытий.

Причиной развития напряжений в тонкопленочных структурах при изменении температуры является различие коэффициентов термического расширения (КТР) пленки и подложки. Например, КТР металлических пленок обычно на порядок превышает КТР кремниевой подложки, которая часто используется для их осаждения. Поэтому при охлаждении системы металлическая пленка-кремниевая подложка от температуры синтеза до комнатной пленка стремится сжаться гораздо сильнее, чем подложка (рис. 8). Однако, поскольку толщина подложки на несколько порядков больше, чем толщина пленки, последняя должна изменять свои размеры так, чтобы соответствовать изменению размеров подложки. В результате в пленке возникают растягивающие термические напряжения. Напротив, при нагревании данной композиции до температуры, превышающей температуру синтеза, в пленке развиваются сжимающие напряжения. Обратная ситуация имеет место в случае оксидных 


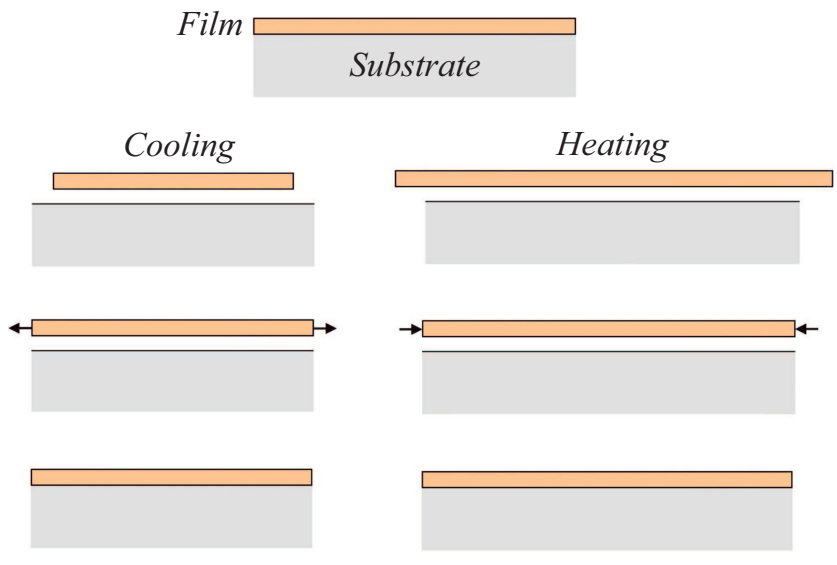

Рис. 8. Схема, иллюстрирующая развитие растягивающих (слева) и сжимающих (справа) термических напряжений в пленке, характеризующейся большим КТР, чем подложка.

и керамических покрытий, нанесенных на металлическую подложку. В процессе охлаждения в таких пленках и покрытиях возникают сжимающие напряжения, а при нагревании - растягивающие.

При охлаждении или нагревании композиции пленка-подложка от температуры $T_{1}$ до температуры $T_{2}$ соответствующая биаксиальная деформация пленки определяется следующим образом:

$$
\varepsilon=-\left(\alpha_{f}-\alpha_{s}\right)\left(T_{2}-T_{1}\right)=-\Delta \alpha \Delta T,
$$

где $\alpha_{f}$ и $\alpha_{s}$ - коэффициенты термического расширения пленки и подложки соответственно.

Если температура изменяется в процессе осаждения пленки, то разные слои пленки будут испытывать различную деформацию. При этом ее среднюю биаксиальную деформацию можно рассчитать с помощью соотношения [94]:

$$
\varepsilon \approx-\Delta \alpha\left(T_{2}-\frac{1}{h} \int_{0}^{h} T(z) d z\right),
$$

где $h$ - толщина пленки, а $d z$ - приращение толщины. Поскольку биаксиальные напряжения связаны с деформацией как

$$
\sigma=\frac{E_{f}}{1-v_{f}} \varepsilon
$$

из выражений (20) и (22) следует, что термические напряжения прямо пропорциональны изменению температуры:

$$
\sigma=-\frac{E_{f}}{\left(1-v_{f}\right)} \Delta \alpha \Delta T
$$

Необходимо отметить, что определить термические напряжения с помощью выражения (23) можно лишь в определенном диапазоне температур, в котором пленка испытывает только упругую деформацию [157]. Когда термические деформации превышают предел текучести пленки, начинается ее пластическое течение посредством различных механизмов, таких, как скольжение дислокаций, диффузионная ползучесть и др. В этом случае термические напряжения нельзя связать с величиной упругой деформации.

Соотношения (20) и (23) могут быть использованы и для оценки термических деформаций и напряжений в многослойных структурах, если общая толщина такой структуры мала по сравнению с толщиной подложки [94]. При этом вычисление напряжений можно проводить отдельно для каждого слоя без учета влияния остальных слоев. Таким образом, как и в случае однослойной пленки, параметрами, определяющими величину термических напряжений при изменении температуры, являются различие КТР данного слоя и подложки, а также модуль упругости слоя. Отсюда вытекает, что порядок слоев в многослойной структуре не оказывает влияния на величину термических напряжений в отдельных слоях.

В случае большой разницы КТР пленки и подложки и сильного изменения температуры термические напряжения могут достигать весьма больших величин [158], учитывая высокие значения пределов текучести и прочности тонкопленочных материалов. Так, согласно [62], охлаждение пластин $\mathrm{Si}$ после их термического окисления привело к развитию сильных сжимающих напряжений в образовавшейся оксидной пленке, основной причиной которых является разница в КТР кремния и его оксида. Вблизи границы раздела $\mathrm{SiO}_{2} / \mathrm{Si}$ сжимающие напряжения достигли $2 \mathrm{GPa}$. Наличие напряжений и деформаций в композиции $\mathrm{SiO}_{2} / \mathrm{Si}$ вызвало образование на границе раздела микроскопических пор, которые в процессе охлаждения превратились в макроскопические полости.

Поскольку, как правило, в тонкопленочных структурах одновременно развиваются и термические и внутренние напряжения, в результате они могут как усиливать (если напряжения одного знака), так и ослаблять друг друга (если напряжения противоположных знаков). Поэтому величина и знак напряжений могут меняться после окончания процесса осаждения пленок. Так, было показано, что при гетероэпитаксии $\mathrm{SrF}_{2}$ и $\mathrm{CaF}_{2}$ на $\mathrm{Si}(111)$ в пленках развиваются сжимающие напряжения несоответствия [159]. Однако при охлаждении этих систем до комнатной температуры напряжения становились растягивающими из-за большого различия КТР пленки и подложки.

\section{2. Напряжения в проводящих пленках, вызванные процессами электромиграции}

Стремление к миниатюризации микроэлектронных устройств вызывает необходимость уменьшения в них ширины и толщины металлических соединений. В результате плотность тока в них достигает $10^{5}-10^{6} \mathrm{~A} / \mathrm{cm}^{2}[160,161]$. Поэтому значительное влияние на развитие напряжений в проводящих пленках оказывают процессы электромиграции. В идеальном случае, 


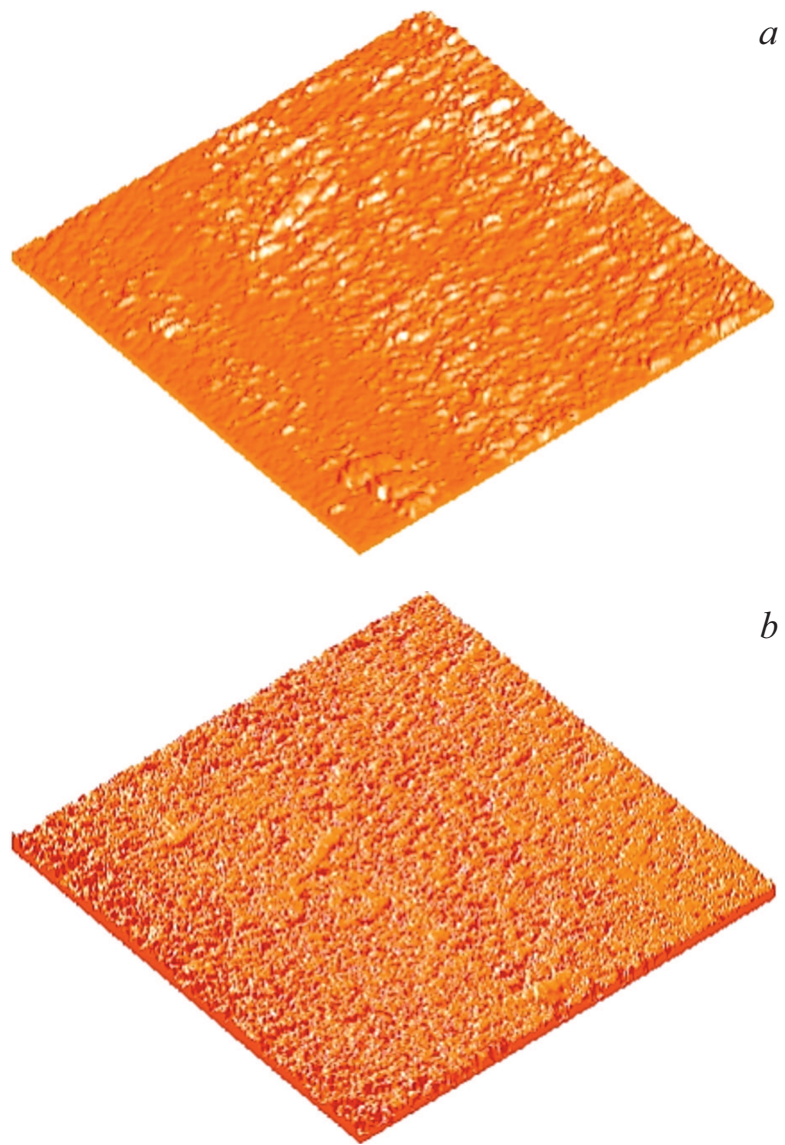

Рис. 9. Формирование холмиков $(a)$ и пор $(b)$ в тонких пленках $\mathrm{Au}$ после пропускания постоянного электрического тока плотностью $2.9 \cdot 10^{5} \mathrm{~A} / \mathrm{cm}^{2}$ в течение $300 \mathrm{~h}$.

когда в однородном тонкопленочном проводнике отсутствуют температурные градиенты, перенос ионов под действием ,электронного ветра“ сам по себе не мог бы вызвать ни увеличения, ни уменьшения плотности материала пленки, а следовательно, и возникновения в ней напряжений. Однако в реальных тонкопленочных проводниках дивергенция потока диффундирующих ионов отлична от нуля, т.е. имеет место нарушение его непрерывности. Оно может быть вызвано целым рядом факторов, почти все из которых связаны с микроструктурой тонких проводящих пленок: градиентами концентрации дефектов, температуры, эффективного заряда, а также градиентами коэффициента диффузии или размера зерен [162]. Нарушение непрерывности потока массопереноса приводит к возникновению в проводящих пленках локальных областей с большей и меньшей плотностью материала и, соответственно, сжимающим и растягивающим напряжениям, которые в общем случае могут быть распределены по их длине случайным образом.

Теоретические расчеты показали [163-167], что повреждения, обусловленные электромиграцией в проводящих металлических пленках, возникают при превы- шении некоторого критического значения напряжений. Сжимающие напряжения вызывают рост холмиков на поверхности пленки, а растягивающие напряжения обусловливают образование полостей (рис. 9). Формирование холмиков происходит за счет пластической деформации материала в определенной зоне, которая первоначально находится вблизи анода, а затем распространяется в сторону катода. В свою очередь, образование и коалесценция полостей постепенно приводят к сдвигу катодного края пленки в сторону анода.

Изучение закономерностей развития напряжений в тонких пленках вследствие электромиграции проведено во многих экспериментальных работах [160,168-171]. Так, в [169] показано, что под действием тока межатомные расстояния в тонкопленочных Al проводниках возрастали около анода и уменьшались около катода. Таким образом, у анода возникали растягивающие напряжения, а у катода - сжимающие. При комнатной температуре растягивающие напряжения в пленке составляли $500 \mathrm{MPa}$. При $T=260^{\circ} \mathrm{C}$ напряжения все еще оставались растягивающими, однако их величина уменьшилась до $50 \mathrm{MPa} \mathrm{вследствие} \mathrm{компенсирующего}$ влияния сжимающих термических напряжений.

Необходимо отметить, что термические напряжения всегда присутствуют в проводящих пленках, поскольку протекающий через них электрический ток высокой плотности обусловливает интенсивное выделение Джоулева тепла, которое приводит к нагреву пленок [171]. В результате в них возникают термические напряжения из-за разницы КТР пленки и подложки. Это затрудняет точное определение величины напряжений, вызванных непосредственно электромиграцией, в пленках, нанесенных на подложку. Для исключения вклада термических напряжений проводятся исследования электромиграции в пленках, находящихся в свободном состоянии, т. е. отделенных от подложки. Так, в [160] показано, что процессы электромиграции вызывают развитие локальных напряжений в тонких пленках $\mathrm{Pt}$, величина которых достигает $2 \mathrm{GPa}$ и более. Основным механизмом релаксации данных напряжений является быстрый рост зерен от 3-5 до $40 \mathrm{~nm}$.

\section{3. Напряжения, возникающие под действием электромагнитного поля}

Существенный вклад в развитие напряжений в тонких пленках могут оказывать эффекты, связанные с воздействием электромагнитного поля. Прежде всего, к ним относятся пьезоэлектрический эффект, электро- и магнитострикция.

Пьезоэлектрический эффект наблюдается в пленках пьезоэлектриков, электрически нейтральных материалов, в элементарной ячейке которых отсутствует центр симметрии [172-175]. Под влиянием внешнего электрического поля такие кристаллы поляризуются, что обусловливает их деформацию. А поскольку пьезоэлектрические пленки не могут свободно деформироваться 
из-за ограничений, накладываемых подложкой, в них возникают механические напряжения. Величина деформаций пьезоэлектриков линейно зависит от величины внешнего электрического поля. Поэтому чем более сильное поле приложено к пленке и чем сильнее ее пьезоэлектрический отклик, тем большие деформации и напряжения будут в ней развиваться. При этом их величина и направление также существенно зависят от направления внешнего электрического поля. Так, в случае, когда поле направлено перпендикулярно плоскости пленки, последняя будет испытывать равноосное сжатие или растяжение [39]. Изменение направления поля на противоположное приводит к изменению знака деформаций и напряжений.

В отличие от пьезоэффекта, электрострикция наблюдается у всех диэлектриков и также обусловлена их поляризацией во внешнем электрическом поле [176]. Однако у объемных материалов деформация, вызванная электрострикцией, при одинаковой напряженности поля на несколько порядков меньше, чем при пьезоэлектрическом эффекте. С другой стороны, деформация при электрострикции пропорциональна квадрату напряженности поля, которая в тонких диэлектрических пленках обратно пропорциональна их толщине [177]. Поэтому деформация пленок, а следовательно, и соответствующие напряжения могут достигать высоких значений. В частности, сильные напряжения, вызванные электрострикцией, развиваются в пленках анодных оксидов металлов, толщина которых может составлять несколько нанометров [178-180].

Следует отметить, что развитие напряжений в диэлектрических пленках при электрострикции обусловлено двумя различными факторами. Во-первых, в результате поляризации на поверхности пленки и на ее границе раздела с подложкой появляются нескомпенсированные (связанные) заряды. Поскольку эти связанные заряды на поверхности пленки и на границе раздела имеют противоположные знаки, между ними возникает кулоновское притяжение. В результате пленка подвергается сжатию в направлении нормали к ее поверхности. Вследствие эффекта Пуассона это должно приводить к увеличению размеров пленки в перпендикулярных направлениях, т.е. к ее равноосному расширению в плоскости, параллельной границе раздела. Однако поскольку подложка препятствует изменению поперечных размеров пленки, в последней развиваются так называемые напряжения Максвелла [178]:

$$
\sigma_{\mathrm{M}}=-\frac{v_{f}}{1-v_{f}} \frac{\varepsilon_{0} \varepsilon_{d}}{2} E_{e}^{2}
$$

где $v_{f}-$ коэффициент Пуассона пленки, $\varepsilon_{d}-$ ее диэлектрическая проницаемость, $\varepsilon_{0}-$ диэлектрическая постоянная, $E_{e l}$ - напряженность электрического поля. Как видно из выражения (24), напряжения Максвелла имеют знак минус, т.е. всегда являются сжимающими, что вытекает из геометрии кулоновского взаимодействия.
Во-вторых, под действием внешнего электрического поля молекулярные диполи стремятся выстроиться вдоль его силовых линий, что также обусловливает деформацию диэлектрической пленки и возникновение в ней напряжений. Данный эффект иногда называют диэлектрострикцией (dielectrostriction) [178]. Согласно $[178,181]$, величину этих напряжений можно записать как:

$$
\sigma_{\mathrm{ES}}=-\frac{v}{1-v} \frac{\varepsilon_{0}}{2}\left[\varepsilon_{d}-\left(\beta_{1}+\beta_{2}\right)\right] E_{e}^{2},
$$

где $\beta_{1}$ и $\beta_{2}$ - электрострикционные параметры, которые зависят от диэлектрической проницаемости пленки. Как видно из выражения (25), знак напряжений, вызванных электрострикцией, определяется соотношением $\varepsilon$ и суммы $\beta_{1}+\beta_{2}$, т.е. в зависимости от диэлектрических свойств пленки данные напряжения могут быть как сжимающими, так и растягивающими. Так, в пленках анодного оксида $\mathrm{TiO}_{2}$ электрострикция приводила к развитию сжимающих напряжений, величина которых достигала $240 \mathrm{MPa}$ [178]. В то же время, согласно [179], в пленках анодного оксида, выращенных на подложке из нержавеющей стали, вследствие электрострикции возникают растягивающие напряжения. Соответственно напряжения (24) и (25) могут как усиливать, так и ослаблять друг друга. Поэтому итоговая величина напряжений, обусловленных электрострикцией, зависит от соотношения $\sigma_{\mathrm{M}}$ и $\sigma_{\mathrm{ES}}$. В случае пленок анодного оксида на нержавеющей стали напряжения Максвелла примерно в 5 раз выше, чем напряжения, обусловленные перестройкой диполей [179]. Следует также отметить, что, поскольку деформация материала при электрострикции пропорциональна квадрату напряженности поля, знак напряжений и деформаций не меняется при изменении направления поля на обратное.

Похожий эффект деформации материала при изменении состояния его намагниченности под действием внешнего магнитного поля носит название магнитострикции. Механизм развития напряжений в тонкопленочных структурах, обусловленных магнитострикцией, аналогичен описанным выше случаям пьезоэффекта и электрострикции $[182,183]$. В зависимости от свойств материала магнитострикция может быть положительной, когда размеры образца увеличиваются вдоль силовых линий магнитного поля, и отрицательной, когда он сжимается в данном направлении. Соответственно в перпендикулярных к силовым линиям направлениях, напротив, происходит сжатие или растяжение. Поэтому в зависимости от свойств материала и направления приложения магнитного поля напряжения в тонких пленках, обусловленные магнитострикцией, могут быть как сжимающими, так и растягивающими. Наиболее значительную роль в возникновении напряжений магнитострикция играет в случае сильномагнитных веществ, обладающих так называемой гигантской магнитострикцией $[184,185]$. В пленках таких материалов деформация может достигать $10^{-2}$, а напряжения $1 \mathrm{GPa}$. 


\section{4. Напряжения, вызванные изменением химического состава и структуры пленок}

Во время хранения и эксплуатации тонкопленочных структур, под действием внешних факторов в них могут происходить различные химические и структурные изменения, которые, как и в процессе роста пленок, приводят к возникновению механических напряжений. Так, пленки силиконовых стекол могут абсорбировать из окружающего воздуха значительное количество воды, при этом в них развиваются сильные сжимающие напряжения [186]. Нагревание данных пленок, напротив, вызывает испарение из них влаги и возникновение растягивающих напряжений. Обратимые изменения напряжений в пленках анодного оксида титана могут быть вызваны абсорбцией и десорбцией водорода [187]. Поглощение водорода пленками $\mathrm{Ni}$ в процессе щелочного электролиза воды вызывает развитие в них сжимающих напряжений $[188,189]$.

\section{5. Напряжения, обусловленные механическими воздействиями}

Наконец, тонкие пленки и покрытия в процессе их эксплуатации могут непосредственно подвергаться различным механическим воздействиям, которые приводят к развитию в них напряжений. Так, в последние годы огромный интерес исследователей вызывают тонкопленочные структуры на гибких подложках, которые имеют широкие перспективы использования при производстве гибких светодиодных экранов, солнечных батарей, различных микроэлектромеханических систем (сенсоров, актюаторов и др.) и т.п. [190-193]. В процессе эксплуатации такие гибкие тонкопленочные структуры испытывают многократную изгибную деформацию, которая приводит к развитию в них неоднородно распределенных механических напряжений, что обусловливает их высокие градиенты [194,195].

Особо следует отметить развитие напряжений в условиях трибологического контакта в покрытиях, предназначенных для защиты различных деталей и механизмов от износа и разрушения. К ним, в частности, относятся твердые керамические покрытия, обладающие повышенной износостойкостью, которые находят широкую область применений от производства режущих инструментов $[196,197]$ до изготовления биомедицинских имплантатов $[198,199]$. В свою очередь, для повышения износостойкости различных контактов и соединителей используются металлические покрытия на основе золота, платины, родия и палладия [200,201]. Во всех случаях напряжения в защитных покрытиях возникают в результате механического контактного взаимодействия между трущимися телами и могут приводить к отслоению и скалыванию покрытий [202,203].

Возникновение напряжений при трибологическом контакте вызвано как силой реакции опоры, которая действует нормально к поверхности контакта, так и тан- генциальной силой трения, обусловленной относительным перемещением соприкасающихся тел. Поскольку на поверхности покрытий, нанесенных на контактирующие тела, всегда присутствуют многочисленные микровыступы различного размера, реальная площадь контакта $S_{r}$ может быть на несколько (1-5) порядков меньше, чем номинальная площадь контакта $S_{n}$ [204]. Среднее напряжение в областях контактирующих микровыступов $\sigma_{a v}$ можно описать следующим выражением [205]:

$$
\sigma_{a v}=\sigma_{n} \frac{S_{n}}{S_{r}}
$$

где $S_{n}$ - сжимающее напряжение в объеме материала, действующее в направлении нормали к поверхности. Из (26) видно, что даже если сжимающие напряжения в объеме материала невелики, средние напряжения в области пятен контакта могут быть очень высокими в случае малых $S_{r}$. Отдельные наиболее высокие микровыступы могут испытывать пластическую деформацию, в то время как остальные деформируются упруго [204]. В случае относительно мягких материалов между микровыступами возникает адгезионное взаимодействие, что приводит к схватыванию контактирующих поверхностей. Последующее относительное перемещение контактирующих тел вызывает разрыв образовавшихся связей. При этом возникающие напряжения могут обеспечивать отрыв не по границе раздела, а на некоторой глубине от нее, т.е. носить не адгезионный, а когезионный характер. Данные напряжения носят циклический характер, т.е. покрытия подвергаются чередующимся циклам растяжения и сжатия. В результате происходит разрушение покрытий посредством вырывания частиц износа.

\section{Заключение}

В работе сделан обзор современных представлений о механизмах развития напряжений в тонких пленках и покрытиях во время их роста, хранения и эксплуатации, а также при различных внешних воздействиях. Проведенный анализ свидетельствует о том, что, хотя в процессе роста поликристаллических пленок могут действовать целый ряд механизмов развития растягивающих напряжений, основной причиной их возникновения на сегодняшний день считается коалесценция островков и возникновение избыточного свободного объема на границах зерен. Причин развития сжимающих напряжений в поликристаллических пленках также существует большое количество, однако выделить какой-либо преобладающий механизм не представляется возможным, поскольку роль каждого из них для разных материалов и в различных условиях осаждения может существенно отличаться.

В процессе роста пленок различные механизмы возникновения внутренних напряжений могут действовать как одновременно, так и последовательно. Более того, 
поскольку одни механизмы могут сменяться другими, в различных слоях пленки внутренние напряжения могут сильно отличаться и даже иметь противоположные знаки. Таким образом, они могут как усиливать, так и компенсировать друг друга. Однако большинство методов определения внутренних напряжений в тонких пленках позволяют найти лишь их усредненную величину, которая часто не дает никакого представления об истинном характере напряженного состояния пленок и не позволяет однозначно установить причины возникновения напряжений. Для выявления точных причин развития напряжений в пленках и соответственно управления их напряженным состоянием необходим послойный анализ напряжений. Подобные исследования могут быть выполнены прежде всего путем непрерывного измерения напряжений непосредственно в процессе осаждения пленок. Послойное измерение напряжений в тонких пленках также возможно и после завершения их формирования, например, с помощью метода рентгеновской дифракции при асимметричной геометрии съемки.

Анализ напряженного состояния, возникающего в тонких пленках при различных внешних воздействиях, также является нетривиальной задачей. Как правило, развитие в пленках внешних напряжений является многоуровневым процессом, когда действие одного внешнего фактора зачастую сопровождается развитием нескольких различных механизмов возникновения напряжений. В частности, высокотемпературное воздействие может одновременно сопровождаться развитием термических напряжений из-за разницы КТР пленки и подложки, а также напряжений, обусловленных структурнофазовыми превращениями в системе пленка-подложка (ростом зерен и аннигиляцией их границ, образованием новых фаз и др.). Еще более усложняют задачу наличие в пленках остаточных внутренних напряжений и возможность их частичной релаксации при внешних воздействиях. Поэтому успешное решение существующих проблем повышения надежности, долговечности и эксплуатационных характеристик тонких пленок и покрытий невозможно без глубокого понимания фундаментальных физических механизмов, лежащих в основе генерации в них внутренних и внешних механических напряжений.

\section{Финансирование работы}

Работа выполнена в рамках государственного задания ИФПМ СО РАН, проект III.23.1.3.

\section{Конфликт интересов}

Авторы заявляют, что у них нет конфликта интересов.

\section{Список литературы}

[1] V.A.C. Haanappel, H.D. van Corbach, T. Fransen, P.G. Gellings. Mater. Sci. Eng. A, 167, 179 (1993). DOI: 10.1016/0921-5093(93)90352-F

[2] B.E. Alaca, M.T.A. Saif, H. Sehitoglu. Acta Mater., 50, 1197 (2002). DOI: 10.1016/S1359- 6454(01)00421-9

[3] P.J.J. Forschelen, A.S.J. Suiker, O. van der Sluis. Int. J. Sol. Struct., 97-98, 284 (2016). DOI: 10.1016/j.jjsolstr.2016.07.020

[4] K. Khaledi, T. Brepols, S. Reese. Mech. Mater., 137 (103142), (2019). DOI: 10.1016/j.mechmat.2019.103142

[5] R. Stylianoua, D. Velic, W. Daves, W. Ecker, A. Stark, N. Schell, M. Tkadletz, N. Schalk, C. Czettl, C. Mitterer. Int. J. Refract. Met. Hard Mater., 86 (105102), (2020). DOI: $10.1016 /$ j.ijrmhm.2019.105102

[6] D.S. Balint, J.W. Hutchinson. J. Appl. Mech., 68, 725 (2001). DOI: $10.1115 / 1.1388012$

[7] L. Lagunegrand, T. Lorriot, R. Harry, H. Wargnier, J.M. Quenisset. Compos. Sci. Technol., 66, 1315 (2006). DOI: 10.1016/j.compscitech.2005.10.010

[8] J.W. Hutchinson, M.Y. He, A.G. Evans. J. Mech. Phys. Solids, 48, 709 (2000). DOI: 10.1016/S0022-5096(99)00050-2

[9] А.Р. Шугуров, А.В. Панин. Физ. мезомех., 12 (3), 21 (2009). [A.R. Shugurov, A.V. Panin. Phys. Mesomech., 13 (1-2), 9 (2010). DOI: 10.1016/j.physme.2010.03.010]

[10] C. Malerba, M. Valentini, R.C.L. Azanza, A. Rinaldi, A. Mittiga. Mater. Design., 108, 725 (2016). DOI: 10.1016/j.matdes.2016.07.019

[11] D.G. Liu, L. Zheng, J.Q. Liu, L.M. Luo, Y.C. Wu. Ceram. Int. 44, 3644 (2018). DOI: 10.1016/j.ceramint.2017.11.115

[12] S.J. Li, K. Wu, H.Z. Yuan, J.Y. Zhang, G. Liu, J. Sun. Surf. Coat. Technol., 362, 35 (2019). DOI: 10.1016/j.surfcoat.2019.01.088

[13] R. Delmelle, S. Michotte, M. Sinnaeve, J. Proost. Acta Mater., 61, 2320 (2013). DOI: $10.1016 /$ j.actamat.2013.01.003

[14] X. Wang, J.J. Vlassak. Mech. Mater., 88, 50 (2015). DOI: 10.1016/j.mechmat.2015.05.001

[15] H. Wang, W. Wang, W. Yang, Y. Zhu, Z. Lin, G. Li. Appl. Surf. Sci., 369, 414 (2016). DOI: 10.1016/j.apsusc.2016.02.044

[16] S.N. Hsiao, F.T. Yuan, S.K. Chen, A.C. Sun, S.H. Su, K.F. Chiu. J. Magn. Magn. Mater., 398, 275 (2016). DOI: $10.1016 /$ j.jmmm.2015.09.034

[17] М.С. Сунгуров, В.А. Финкель. ЖТФ, 88 (8), 1216 (2018). DOI: $10.21883 /$ JTF.2018.08.46312.1824 [M.S. Sungurov, V.A. Finkel. Tech. Phys., 63 (8), 1182 (2018). DOI: $10.1134 / \mathrm{S} 1063784218080200]$

[18] В.М. Прохоров, Е.В. Гладких, Л.А. Иванов, В.В. Аксененков, А.Н. Кириченко. ЖТФ, 89(5), 704 (2019). DOI: 10.21883/JTF.2019.05.47472.17318 [V.M. Prokhorov, E.V. Gladkikh, L.A. Ivanov, V.V. Aksenenkov, A.N. Kirichenko. Tech. Phys., 64(5), 654 (2019). DOI: 10.1134/S1063784219050190]

[19] Z.S. Ma, Y.C. Zhou, S.G. Long, C. Lu. Surf. Coat. Technol., 207, 305 (2012). DOI: 10.1016/j.surfcoat.2012.07.002

[20] X. Zhang, M. Watanabe, S. Kuroda. Eng. Fract. Mech., 110, 314 (2013). DOI: 10.1016/j.engfracmech.2013.08.016

[21] G.A. Cheng, D.Y. Han, C.L. Liang, X.L. Wu, R.T. Zheng. Surf. Coat. Technol., 228, s328 (2013).

DOI: 10.1016/j.surfcoat.2012.05.108 
[22] O.P. Oladijo, A.M. Venter, L.A. Cornish. Int. J. Refract. Met. Hard Mater., 44, 68 (2014). DOI: $10.1016 /$ j.ijrmhm.2014.01.009

[23] B. Vierneusel, L. Benker, S. Tremmel, M. Göken, B. Merle. Thin Solid Films, 638, 159 (2017). DOI: $10.1016 /$ j.tsf.2017.06.016

[24] T. Poirié, T. Schmitt, E. Bousser, L. Martinu, J.-E. KlembergSapieha. Tribol. Int., 109, 355 (2017). DOI: $10.1016 /$ j.triboint.2016.12.053

[25] Y. Xi, Y. Bai, K. Gao, X. Pang, H. Yang, L. Yan, A.A. Volinsky. Ceram. Int., 44, 15851 (2018). DOI: $10.1016 /$ j.ceramint.2018.05.266

[26] M.S. Bae, C. Park, D. Shin, S.M. Lee, I. Yun. Solid State Electron., 133, 1 (2017). DOI: 10.1016/j.sse.2017.04.003

[27] M.H. Hong, D.I. Shim, H.H. Cho, H.H. Park. Appl. Surf. Sci., 446, 160 (2018). DOI: 10.1016/j.apsusc.2018.01.283

[28] T. Wang, B. Wang, A. Haque, M. Snure, E. Heller, N. Glavin. Microelectron. Reliab., 81, 181 (2018). DOI: $10.1016 /$ j.microrel.2017.12.033

[29] Ю.А. Бойков, И.Т. Серенков, В.И. Сахаров, B.A. Данилов. ФТТ, $\mathbf{6 0}(1), \quad 171$ (2018). DOI: 10.21883/FTT.2018.01.45305.213 [Yu.A. Boikov, I.T. Serenkov, V.I. Sakharov, V.A. Danilov. Phys. Solid State, 60 (1), 173 (2018). DOI: 10.1134/S1063783418010067]

[30] K. Sun, Q. Li, H. Guo, Y. Yang, L. Li. J. Alloys Compd., 663, 645 (2016). DOI: 10.1016/j.jallcom.2015.12.193

[31] Q. Liu, W. Zhou, J. Ding, M. Xiao, Z.J. Yu, H. Xu, W.G. Mao, Y.M. Pei, F.X. Li, X. Feng, D.N. Fang. J. Magn. Magn. Mater., 423, 90 (2017). DOI: 10.1016/j.jmmm.2016.09.079

[32] Y. Tan, K. Liang, Z. Mei, P. Zhou, Y. Liu, Y. Qi, Z. Ma, T. Zhang. Ceram. Int., 44, 5564 (2018). DOI: $10.1016 /$ j.ceramint.2017.12.200

[33] K. Kumar, P. Arun, C.R. Kant, N.C. Mehra, L. Makinistian, E.A. Albanesi. J. Phys. Chem. Solids, 71, 163 (2010). DOI: 10.1016/j.jpcs.2009.10.013

[34] B. Sarma, B.K. Sarma. J. Alloys Compd., 734, 210 (2018). DOI: 10.1016/j.jallcom.2017.11.028

[35] М.Л. Савченко, Н.Н. Васильев, А.С. Ярошевич, Д.А. Козлов, 3.Д. Квон, Н.Н. Михайлов, С.А. Дворецкий. ФТТ, 60 (4), 774 (2018).

DOI: 10.21883/FTT.2018.04.45692.309

[M.L. Savchenko, N.N. Vasil'ev, A.S. Yaroshevich, D.A. Kozlov, Z.D. Kvon, N.N. Mikhailov, S.A. Dvoretskii. Phys. Solid State, 60 (4), 778 (2018). DOI: $10.1134 / \mathrm{S} 1063783418040285]$

[36] W. Li, P. Li, H. Zeng, Z. Yue, J. Zhai. Mater. Lett., 162, 135 (2016). DOI: 10.1016/j.matlet.2015.09.137

[37] Y. Wang, K.Y. Li, F. Scenini, J. Jiao, S.J. Qu, Q. Luo, J. Shen. Surf. Coat. Technol., 302, 27 (2016). DOI: 10.1016/j.surfcoat.2016.05.034

[38] S. Saha, M. Tomar, V. Gupta. Enzyme Microb. Tech., 79-80, 63 (2015). DOI: 10.1016/j.enzmictec.2015.07.008

[39] L.B. Freund, S. Suresh. Thin Film Materials: Stress, Defect Formation and Surface Evolution. (Cambridge University Press, Cambridge, 2003). 820 p.

[40] A. Fluri, D. Pergolesi, A. Wokaun, T. Lippert. / Phys. Rev. B., 97, 125412-1-10 (2018). DOI: 10.1103/PhysRevB.97.125412

[41] S.A. Kukushkin, A.V. Osipov. J. Appl. Phys., 113, 024909 1-7 (2013). DOI: $10.1063 / 1.4773343$

[42] F.S. Frank, J.H. van der Merwe. Proc. Roy. Soc. London A, 198, 205 (1949). DOI: 10.1098/rspa.1949.0095
[43] F.C. Frank, J.H. van der Merwe. Proc. Roy. Soc. London A, 198, 216 (1949). DOI: 10.1098/rspa.1949.0096

[44] V.A. Shchukin, A.I. Borovkov, N.N. Ledentsov, P.S. Kop'ev. Phys. Rev. B, 51, 17767 (1995).

DOI: 10.1103/PhysRevB.51.17767

[45] О.П. Пчеляков, Ю.Б. Болховитянов, А.В. Двуреченский, Л.В. Соколов, А.И. Никифоров, А.И. Якимов, Б. Фойхтлендер. ФТП, 34, 1281 (2000). [O.P. Pchelyakov, Yu.B. Bolkhovityanov, A.V. Dvurechenskii, L.V. Sokolov, A.I. Nikiforov, A.I. Yakimov, B. Voigtländer. Semiconductors, 34, 1229 (2000). DOI: 10.1134/1.1325416]

[46] Ю.Б. Болховитянов, О.П. Пчеляков, С.И. Чикичев. УФН, 171, 689 (2001). [Yu.B. Bolkhovityanov, O.P. Pchelyakov, S.I. Chikichev. Phys. Usp., 44, 655 (2001). DOI: 10.1070/PU2001v044n07ABEH000879]

[47] М.Ю. Гуткин, А.М. Смирнов. ФТТ, 58, 1558 (2016). [M.Yu. Gutkin, A.M. Smirnov. Phys. Solid State, 58, 1611 (2016). DOI: 10.1134/S1063783416080138]

[48] H.V. Thang, S. Tosoni, G. Pacchioni. Appl. Surf. Sci., 483, 133 (2019). DOI: 10.1016/j.apsusc.2019.03.240

[49] M.-J. Casanove, A. Alimoussa, M. Schwerdtfeger, S. Gaubert, H. Moriceau, J.-C. Villegier. Mater. Sci. Eng. B, 33, 162 (1995). DOI: 10.1016/0921-5107(94)01182-6

[50] Y. Obayashi, K. Shintani. J. Appl. Phys., 84, 3141 (1998). DOI: $10.1063 / 1.368468$

[51] M. Copel, M.C. Reuter, M. Horn-von Hoegen, R.M. Tromp. Phys. Rev. B, 42, 11682 (1990). DOI: $10.1103 /$ PhysRevB.42.11682

[52] R.J. Asaro, W.A. Tiller. Metall. Trans., 3, 1789 (1972). DOI: $10.1007 / \mathrm{BF} 02642562$

[53] М.А. Гринфельд. ДАН СССР. 290, 1358 (1986).

[54] D.J. Srolovitz. Acta Metall., 37, 621 (1989). DOI: 10.1016/0001-6160(89)90246-0

[55] Y. Pang, R. Huang. Phys. Rev. B, 74, 075413 (2006). DOI: 10.1103/PhysRevB.74.075413

[56] J. Berrehar, C. Caroli, C. Lapersonne-Meyer, M. Schott. // Phys. Rev. B, 46, 13487 (1992). DOI: 10.1103/PhysRevB.46.13487

[57] M. Volmer, A. Weber. Z. Phys. Chem., 119, 277 (1926).

[58] I. Lucci, S. Charbonnier, L. Pedesseau, M. Vallet, L. Cerutti, J.-B. Rodriguez, E. Tournié, R. Bernard, A. Létoublon, N. Bertru, A. Le Corre, S. Rennesson, F. Semond, G. Patriarche, L. Largeau, P. Turban, A. Ponchet, C. Cornet. Phys. Rev. Mater., 2, 060401-1-6 (2018). DOI: 10.1103/PhysRevMaterials.2.060401

[59] I.N. Stranski, L. Krastanov. Zur Sitzungsber. Akad. Wiss. Wien. Math.-Naturwiss. K1. IIb. 146, 797 (1938).

[60] D.J. Eaglesham, M. Cerullo. Phys. Rev. Lett., 64, 1943 (1990). DOI: 10.1103/PhysRevLett.64.1943

[61] J.E. Prieto, I. Markov. Surf. Sci., 664, 172 (2017). DOI: $10.1016 /$ j.susc.2017.05.018

[62] M.D. Rouhani, A.M. Gue, R. Malek, G. Bouyssou, D. Esteve. Mater. Sci. Eng. B, 37, 252 (1996). DOI: $10.1016 / 0921-5107(95) 01452-7$

[63] R.C. Cammarata, T.M. Trimble, D.J. Srolovitz. J. Mater. Res., 15, 2468 (2000). DOI: 10.1557/JMR.2000.0354

[64] W.D. Nix, B.M. Clemens. J. Mater. Res., 14, 3467 (1999). DOI: $10.1557 / J M R .1999 .0468$

[65] J. Leib, R. Mönig, C.V. Thompson. Phys. Rev. Lett., 102, 256101 (2009). DOI: 10.1103/PhysRevLett.102.256101 
[66] G. Abadias, A. Fillon, J.J. Colin, A. Michel, C. Jaouen. Vacuum, 100, 36 (2014). DOI: $10.1016 /$ j.vacuum.2013.07.041

[67] E. Chason, P.R. Guduru. J. Appl. Phys., 119, 191101 (2016). DOI: $10.1063 / 1.4949263$

[68] C. Furgeaud, L. Simonot, A. Michel, C. Mastail, G. Abadias. Acta Mater., 159, 286 (2018). DOI: $10.1016 /$ j.actamat.2018.08.019

[69] R. Koch. Surf. Coat. Technol., 204, 1973 (2010). DOI: 10.1016/j.surfcoat.2009.09.047

[70] D. Magnfalt, A. Fillon, R.D. Boyd, U. Helmersson, K. Sarakinos, G. Abadias. J. Appl. Phys., 119, 055305 (2016). DOI: 10.1063/1.4941271

[71] D.L. Ma, P.P. Jing, Y.L. Gong, B.H. Wu, Q.Y. Deng, Y.T. Li, C.Z. Chen, Y.X. Leng, N. Huang. Vacuum, 160, 226 (2019). DOI: $10.1016 /$ j.vacuum.2018.11.039

[72] D.P. Adams, L.J. Parfitt, J.C. Biello, S.M. Yalisove, Z.U. Rek. Thin Solid Films, 266, 52 (1995). DOI: $10.1016 / 0040-6090(95) 00603-6$

[73] C. Hua, X. Yan, J. Wei, J. Guo, J. Liu, L. Chen, L. Hei, C. Li. Diam. Relat. Mater., 73, 62 (2017). DOI: $10.1016 /$ j.diamond.2016.12.008

[74] M. Laugier. Vacuum, 31, 155 (1981). DOI: $10.1016 / 0042-207 X(81) 90007-5$

[75] R.C. Cammarata. Prog. Surf. Sci., 46, 1 (1994). DOI: 10.1016/0079-6816(94)90005-1

[76] C. Friesen, C.V. Thompson. Phys. Rev. Lett., 89, 126103 (2002). DOI: 10.1103/PhysRevLett.89.126103

[77] C. Friesen, S.C. Seel, C.V. Thompson. J. Appl. Phys., 95, 1011 (2004). DOI: $10.1063 / 1.1637728$

[78] C.W. Pao, D.J. Srolovitz, C.V. Thompson. Phys. Rev. B, 74, 155437 (2006). DOI: 10.1103/PhysRevB.74.155437

[79] R. Abermann, R. Koch. Thin Solid Films, 129, 71 (1985). DOI: 10.1016/0040- 6090(85)90096-3

[80] R. Abermann. Thin Solid Films, 186, 233 (1990). DOI: 10.1016/0040-6090(90)90145-4

[81] R. Abermann. Vacuum, 41, 1279 (1990). DOI: $10.1016 / 0042-207 X(90) 93933-A$

[82] D.W. Hoffman, J.A. Thornton. J. Vac. Sci. Technol., 20, 355 (1982). DOI: $10.1116 / 1.571463$

[83] M. Janda, O. Stefan. Thin Solid Films, 112, 127 (1984). DOI: $10.1016 / 0040-6090(84) 90490-5$

[84] J.A. Floro, S.J. Hearne, J.A. Hunter, P. Kotula, E. Chason, S.C. Seel, C.V. Thompson. J. Appl. Phys., 89, 4886 (2001). DOI: $10.1063 / 1.1352563$

[85] H.Z. Yu, C.V. Thompson. Acta Mater., 67, 189 (2014). DOI: $10.1016 /$ j.actamat.2013.12.031

[86] C.V. Thompson, R. Carel. J. Mech. Phys. Solids, 44, 657 (1996). DOI: 10.1016/0022-5096(96)00022-1

[87] H.K. Pulker. Thin Solid Films, 89, 191 (1982). DOI: $10.1016 / 0040-6090(82) 90447-3$

[88] R.W. Hoffman. In: Physics of Thin Films. Vol. 3, ed. by G. Hass, R.E. Thun. (Academic Press, New York, 1966). P. 211.

[89] R.W. Hoffman. Thin Solid Films, 34, 185 (1976). DOI: 10.1016/0040-6090(76)90453-3

[90] L.B. Freund, E. Chason. J. Appl. Phys., 89, 4866 (2001). DOI: $10.1063 / 1.1359437$

[91] K.L. Johnson, K. Kendall, A.D. Roberts. Proc. R. Soc. Lond. A, 324, 301 (1971). DOI: 10.1098/rspa.1971.0141

[92] R. Koch. J. Phys.: Condens. Matter., 6, 9519 (1994). DOI: $10.1088 / 0953-8984 / 6 / 45 / 005$
[93] P. Chaudhari. J. Vac. Sci. Technol., 9, 520 (1972). DOI: $10.1116 / 1.1316674$

[94] M.F. Doerner, W.D. Nix. Crit. Rev. Solid State Mater. Sci., 14, 225 (1988). DOI: 10.1080/10408438808243734

[95] H.J. Frost, F. Spaepen, M.F. Ashby. Scripta Metall., 16, 1165 (1982). DOI: 10.1016/0036-9748(82)90089-8

[96] R. Abermann, R. Koch, R. Kramer. Thin Solid Films, 58, 365 (1979). DOI: 10.1016/0040-6090(79)90272-4

[97] F. Spaepen. Acta mater., 48, 31 (2000). DOI: $10.1016 / \mathrm{S} 1359-6454(99) 00286-4$

[98] A. Gonzalez-Gonzalez, G.M. Alonzo-Medina, A.I. Oliva, C. Polop, J.L. Sacedón, E. Vasco. Phys. Rev. B, 84, 155450 (2011). DOI: 10.1103/PhysRevB.84.155450

[99] A. Gonzalez-Gonzalez, C. Polop, E. Vasco. Phys. Rev. Lett., 110, 056101 (2013). DOI: 10.1103/PhysRevLett.110.056101

[100] E. Chason, B.W. Sheldon, L.B. Freund, J.A. Floro, S.J. Hearne. Phys. Rev. Lett., 88, 156103 (2002). DOI: 10.1103/PhysRevLett.88.156103

[101] S.J. Tello, A.F. Bower, E. Chason, B.W. Sheldon. Phys. Rev. Lett., 98, 216104 (2007). DOI: 10.1103/PhysRevLett.98.216104

[102] E. Chason. Thin Solid Films, 526, 1 (2012). DOI: 10.1016/j.tsf.2012.11.001

[103] E. Chason, J.W. Shin, S.J. Hearne, L.B. Freund. J. Appl. Phys., 111, 083520 (2012). DOI: $10.1063 / 1.4704683$

[104] E. Chason, A.F. Bower. J. Appl. Phys., 125, 115304 (2019). DOI: $10.1063 / 1.5085313$

[105] J.W. Shin, E. Chason. Phys. Rev. Lett., 103, 056102 (2009). DOI: 10.1103/PhysRevLett.103.056102

[106] H.Z. Yu, C.V. Thompson. Appl. Phys. Lett., 104, 141913 (2014). DOI: $10.1063 / 1.4871214$

[107] D. Flötotto, Z.M. Wang, L.P.H. Jeurgens, E.J. Mittemeijer. J. Appl. Phys., 118, 055305 (2015). DOI: 10.1063/1.4928162

[108] E. Chason, A.M. Engwall, Z. Rao, T. Nishimura. J. Appl. Phys., 123, 185305 (2018). DOI: 10.1063/1.5030740

[109] S.J. Hearne, J.A. Floro. J. Appl. Phys., 97, 014901 (2005). DOI: $10.1063 / 1.1819972$

[110] E. Chason, J.W. Shin, C.-H. Chen, A.M. Engwall, C.M. Miller, S.J. Hearne, L.B. Freund. J. Appl. Phys., 115, 123519 (2014). DOI: 10.1063/1.4870051

[111] A.M. Engwall, Z. Rao, E. Chason. Mater. Design, 110, 616 (2016). DOI: 10.1016/j.matdes.2016.07.089

[112] E. Chason, A.M. Engwall, F. Pei, M. Lafouresse, U. Bertocci, G. Stafford, J.A. Murphy, C. Lenihan, D.N. Buckley. J. Electrochim. Soc., 160, D3285 (2013). DOI: $10.1149 / 2.048312$ jes

[113] A.M. Engwall, Z. Rao, E. Chason. J. Electrochim. Soc., 160, D828 (2017). DOI: 10.1149/2.0921713jes

[114] R. Koch, D. Hu, A.K. Das. Phys. Rev. Lett., 94, 146101 (2005). DOI: 10.1103/PhysRevLett.94.146101

[115] H. Windischmann. Crit. Rev. Solid State Mater. Sci., 17, 547 (1992). DOI: 10.1080/10408439208244586

[116] J.A. Floro, E. Chason, R.C. Cammarata, D.J. Srolovitz. MRS Bull., 27, 19 (2002). DOI: 10.1557/mrs2002.15.

[117] G.C.A.M. Janssen. Thin Solid Films, 515, 6654 (2007). DOI: 10.1016/j.tsf.2007.03.007

[118] G. Abadias, E. Chason, J. Keckes, M. Sebastiani, G.B. Thompson, E. Barthel, G.L. Doll, C.E. Murray, C.H. Stoessel, L. Martinu. J. Vac. Sci. Technol. A, 36, 020801 (2018). DOI: $10.1116 / 1.5011790$ 
[119] S.O. Mbam, S.E. Nwonu, O.A. Orelaja, U.S. Nwigwe, X.F. Gou. Mater. Res. Express, 6, 122001 (2019). DOI: 10.1088/2053-1591/ab52cd

[120] P.Eh. Hovsepian, A.A. Sugumaran, Y. Purandare, D.A.L. Loch; A.P. Ehiasarian. Thin Solid Films, 562, 132 (2014). DOI: 10.1016/j.tsf.2014.04.002

[121] F. Cemin, G. Abadias, T. Minea, D. Lundin. Thin Solid Films, 688, 137335 (2019). DOI: 10.1016/j.tsf.2019.05.054

[122] F.M. D’Heurle, J.M. Harper. Thin Solid Films, 171, 81 (1989). DOI: 10.1016/0040-6090(89)90035-7

[123] J.A. Thornton, D.W. Hoffman. Thin Solid Films, 171, 5 (1989). DOI: 10.1016/0040-6090(89)90030-8

[124] G. Carter. J. Phys. D. Appl. Phys., 27, 1046 (1994). DOI: $10.1088 / 0022-3727 / 27 / 5 / 024$

[125] H. Windischmann. J. Appl. Phys., 62, 1800 (1987). DOI: $10.1063 / 1.339560$

[126] L. Romano-Brandt, E. Salvatia, E. Le Bourhis, T. Moxhama, I.P. Dolbnyac, A.M. Korsunsky. Surf. Coat. Technol., 381, 125142 (2020). DOI: 10.1016/j.surfcoat.2019.125142

[127] F. Cemin, G. Abadias, T. Minea, C. Furgeaud, F. Brisset, D. Solas, D. Lundin. Acta Mater., 141, 120 (2017). DOI: $10.1016 /$ j.actamat.2017.09.007

[128] G.C.A.M. Janssen, J.-D. Kamminga. Appl. Phys. Lett., 85, 3086 (2004). DOI: 10.1063/1.1807016

[129] J.-D. Kamminga, Th.H. de Keijser, R. Delhez, E.J. Mittemeijer. J. Appl. Phys., 88, 6332 (2000). DOI: $10.1063 / 1.1319973$

[130] C.M. Gilmore, J.A. Sprague. Thin Solid Films, 419, 18 (2002). DOI: 10.1016/S0040-6090(02)00609-0

[131] J.-D. Kamminga, Th.H. de Keijser, R. Delhez, E.J. Mittemeijer. Thin Solid Films, 317, 169 (1998). DOI: 10.1016/S0040-6090(97)00614-7

[132] G. Abadias, Y.Y. Tse. J. App. Phys., 95, 2414 (2004). DOI: $10.1063 / 1.1646444$

[133] A. Debelle, G. Abadias, A. Michel, C. Jaouen. J. Appl. Phys., 84, 5034 (2004). DOI: 10.1063/1.1763637

[134] E. Chason, M. Karlson, J.J. Colin, D. Magnfält, K. Sarakinos, G. Abadias. J. Appl. Phys., 119, 145307 (2016). DOI: $10.1063 / 1.4949263$

[135] A. Fillon, G. Abadias, A. Michel, C. Jaouen. Thin Solid Films, 519, 1655 (2010). DOI: 10.1016/j.tsf.2010.07.091

[136] J.J. Colin, G. Abadias, A. Michel, C. Jaouen. Acta Mater., 126, 481 (2017). DOI: 10.1016/j.actamat.2016.12.030

[137] T. Kaub, Z. Rao, E. Chason, G.B. Thompson. Surf. Coat. Technol., 357, 939 (2019).

DOI: $10.1016 / j . s u r f c o a t .2018 .10 .059$

[138] J.B. Gibson, A.N. Goland, M. Milgram, G.H. Vineyard. Phys. Rev., 120, 1229 (1960). DOI: 10.1103/PhysRev.120.1229

[139] S. Zhang, H.T. Johnson, G.J. Wagner, W.K. Liu, K.J. Hsia. Acta Mater., 51, 5211 (2003). DOI: 10.1016/S13596454(03)00385-9

[140] L.A. Davis. In: Metallic glasses, ed. by J.J. Gilman, H.J. Leamy. (American Society for Metals, Metals Park, Ohio, 1978). P. 190

[141] T. Nonaka, G. Ohbayashi, Y. Toriumi, Y. Mori, H. Hashimoto. Thin Solid Films, 370, 258 (2000). DOI: 10.1016/S0040-6090(99)01090-1.

[142] T.P. Leervad Pedersen, J. Kalb, W.K. Njoroge, D. Wamwangi, M. Wuttig, F. Spaepen. Appl. Phys. Lett., 79, 3597 (2001). DOI: $10.1063 / 1.1415419$
[143] B. Ben Yahia, M.S. Amara, M. Gallard, N. Burle, S. Escoubas, C. Guichet, M. Putero, C. Mocuta, M.I. Richard, R. Chahine, C. Sabbione, M. Bernard, L. Fellouh, P. Noé, O. Thom. Micro Nano Eng., 1, 63 (2018). DOI: $10.1016 /$ j.mne.2018.10.001

[144] W.Q. Lia, F.R. Liu, Y.Z. Zhang, G. Hana, W.N. Hana, F. Liu, N.X. Sund. J. Non-Cryst. Solids, 516, 99 (2019). DOI: 10.1016/j.jnoncrysol.2019.04.004

[145] H. Horikoshi, N. Tamura. Jpn. J. Appl. Phys., 2, 328 (1963). DOI: 10.1143/JJAP.2.328

[146] G.E. White, H. Chen. J. Appl. Phys., 68, 3317 (1990). DOI: $10.1063 / 1.346384$

[147] P.P. Buaud, F.M. d'Heurle, E.A. Irene, B.K. Patnaik, N.R. Parikh. J. Vac. Sci. Technol. B, 9, 2536 (1991). DOI: $10.1116 / 1.585688$.

[148] P. Gergaud, O. Thomas, B. Chenevier. J. Appl. Phys., 94, 1584 (2003). DOI: 10.1063/1.1590059

[149] S.-L. Zhang, F.M. d'Heurle. Thin Solid Films, 213, 34 (1992). DOI: 10.1016/0040-6090(92)90471-M

[150] A. Fillon, G. Abadias, A. Michel, C. Jaouen, P. Villechaise. Phys. Rev. Lett., 104, 096101 (2010).

DOI: 10.1103/PhysRevLett.104.096101

[151] B. Krause, G. Abadias, C. Furgeaud, A. Michel, A. Resta, A. Coati, Y. Garreau, A. Vlad, D. Hauschild, T. Baumbach. ACS Appl. Mater. Interfaces, 11, 39315 (2019). DOI: 10.1021/acsami.9b11492

[152] D.S. Gardner, T.L. Michalka, P.A. Flinn, T.W. Jr. Barbee, K.C. Saraswat, J.D. Meindl. Proc. $2^{\text {nd }}$ Int. IEEE VLSI Multilevel Interconnection Conf. (Santa Clara, 1985), P. 102.

[153] D. Winau, R. Koch, M. Weber, K.-H. Rieder, R.K. Garg, T. Schurig, H. Koch. Appl. Phys. Lett., 61, 279 (1992). DOI: $10.1063 / 1.107937$

[154] G. Thurner, R. Abermann. Vacuum, 41, 1300 (1990). DOI: 10.1016/0042-207X(90)93939-G.

[155] Y. Xu, X.-T. Yan. Chemical Vapour Deposition: An integrated engineering design for advanced materials (Springer-Verlag, London, 2010)

[156] V.K. Tolpygo, D.R. Clarke. Acta Mater., 47, 3589 (1999). DOI: 10.1016/S1359-6454(99)00216-5

[157] M. Murakami. J. Vac. Sci. Technol., 9, 2469 (1991). DOI: $10.1116 / 1.577258$

[158] L. Rossmann, M. Northam, B. Sarley, L. Chernova, V. Viswanathan, B. Harder, S. Raghavan. Surf. Coat. Technol., 378, 125047 (2019). DOI: 10.1016/j.surfcoat.2019.125047

[159] L.J. Schowalter, W. Li. Appl. Phys. Lett., 62, 696 (1993). DOI: $10.1063 / 1.108843$

[160] S. Kumar, M.T. Alam, Z. Connell, M.A. Haque. Scripta Mater., 65, 277 (2011).

DOI: 10.1016/j.scriptamat.2011.04.030

[161] Y.H. Oh, S.I. Kim, M. Kim, S.Y. Lee, Y.W. Kim. Ultramicroscopy, 181, 160 (2017). DOI: $10.1016 /$ j.ultramic.2017.05.018

[162] Ф. д’Эрл, П. Хо. В сб.: Тонкие пленки - взаимная диффузия и реакиии, под ред. Дж. Поута, К. Ту, Дж. Мейера. (Мир, М., 1982). с. 250. [F.M. d'Heurle, P.S. Ho. In: Thin films - interdiffusion and reactions, ed. by J.M. Poate, K.N. Tu, J.W. Mayer (Wiley, New York, 1978). P. 243.]

[163] R. Kirchheim. Acta Metall. Mater., 40, 309 (1992). DOI: 10.1016/0956-7151(92)90305-X

[164] A. Korhonen, P. Børgesen, K.N. Tu, C.Y. Li. J. Appl. Phys., 73, 3790 (1993). DOI: 10.1063/1.354073 
[165] L. Klinger, E. Glickman, A. Katsman, L. Levin. Mater. Sci. Eng. B, 23, 15 (1994). DOI: 10.1016/0921-5107(94)90271-2

[166] E.E. Glickman. Phys. Low-Dimens. Struct., (5-6), 53 (1998).

[167] L. Filipovic. Microelectron. Reliab., 97, 38 (2019). DOI: 10.1016/j.microrel.2019.04.005

[168] I.A. Blech, C. Herring. Appl. Phys. Lett., 29, 131 (1976). DOI: $10.1063 / 1.89024$

[169] P.-C. Wang, G.S. Cargill III, I.C. Noyan, C.-K. Hu. Appl. Phys. Lett., 72, 1296 (1998). DOI: 10.1063/1.120604

[170] K.N. Tu. J. Appl. Phys., 94, 5451 (2003). DOI: $10.1063 / 1.1611263$

[171] K.N. Tu, Y. Liu, M. Li. Appl. Phys. Rev. 4, 011101 (2017). DOI: $10.1063 / 1.4974168$

[172] A. Ababneh, U. Schmid, J. Hernando, J.L. SanchezRajas, H. Seidel. Mater. Sci. Eng. B, 172, 253 (2010). DOI: $10.1016 /$ j.mseb.2010.05.026

[173] H. Liu, F. Zeng, G. Tang, F. Pan. Appl. Surf. Sci. 270, 225 (2013). DOI: 10.1016/j.apsusc.2013.01.005

[174] S. Dutta, A.A. Jeyaseelan, S. Sruthi. Thin Solid Films, 562, 190 (2014). DOI: 10.1016/j.tsf.2014.04.072

[175] L. Yin, W. Hu, M. Wu, J. Shi, J. Zhu. J. Mater. Sci: Mater. Electron., 30, 14072 (2019). DOI: $10.1007 / \mathrm{s} 10854-019-01772-5$

[176] R.E. Newnham, V. Sundar, R. Yimnirun, J. Su, Q.M. Zhang. J. Phys. Chem. B, 101, 10141 (1997). DOI: $10.1021 / \mathrm{jp} 971522 \mathrm{c}$

[177] В.А. Иванов, А.С. Сахаров, М.Е. Коныжев. УПФ, 1, 697 (2013).

[178] J.-F. Vanhumbeeck, J. Proost. Electrochim. Acta, 53, 6165 (2008). DOI: 10.1016/j.electacta.2007.11.028

[179] A.H. Heuer, H. Kahn, P.M. Natishan, F.J. Martin, L.E. Cross. Electrochim. Acta, 58, 157 (2011). DOI: $10.1016 /$ j.electacta.2011.09.027

[180] F. Blaffart, Q. Van Overmeere, T. Pardoen, J. Proost. J. Solid State Electrochem., 17, 1945 (2013). DOI: $10.1007 / \mathrm{s} 10008-013-2036-0$

[181] R.M. McMeeking, C.M. Landis. J. Appl. Mech., 72, 581 (2005). DOI: 10.1115/1.1940661

[182] J.-Ph. Jay, F. Le Berre, S.P. Pogossian, M.V. Indenbom. J. Magn. Mag. Mater., 322, 2203 (2010). DOI: 10.1016/j.jmmm.2010.02.011

[183] R. Varghese, R. Viswan, K. Joshi, S. Seifikar, Y. Zhou, J. Schwartz, S. Priya. J. Magn. Mag. Mater., 363, 179 (2014). DOI: $10.1016 /$ j.jmmm.2014.03.076

[184] S.H. Lim, H.J. Kim, S.M. Na, S.J. Suh. J. Magn. Mag. Mater., 239, 546 (2002). DOI: 10.1016/S0304-8853(01)00660-6

[185] S.S. Aplesnin, A.N. Masyugin, M.N. Sitnicov, U.I. Rybina, T. Ishibashi. J. Magn. Mag. Mater., 464, 44 (2018). DOI: $10.1016 /$ j.jmmm.2018.05.038

[186] A. Shintani, S. Sugaki, H. Nakashima. J. Appl. Phys., 51, 4197 (1980). DOI: 10.1063/1.328277.

[187] J.-D. Kim, S.-I. Pyun, M. Seo. Electrochim. Acta, 48, 1123 (2003). DOI: 10.1016/S0013-4686(02)00823-X

[188] S.M. Kim, S.H. Jin, Y.J. Lee, M.H. Lee. Electrochim. Acta, 252, 67 (2017). DOI: 10.1016/j.electacta.2017.08.157

[189] J. Proost, A. Delvaux. Electrochim. Acta, 322, 134752 (2019). DOI: 10.1016/j.electacta.2019.134752

[190] O. Cao, J.A. Rogers. Adv. Mater., 21, 29 (2009). DOI: $10.1002 /$ adma.200801995

[191] J.A. Rogers, T. Someya, Y. Huang. Science, 327, 1603 (2010). DOI: $10.1126 /$ science.1182383
[192] X.M. Luo, B. Zhang, G.P. Zhang. Nano. Mater. Sci., 1, 198 (2019). DOI: 10.1016/j.nanoms.2019.02.003

[193] W. Gao, Y. Zhu, Y. Wang, G. Yuan, J.M. Liu. J. Materiomics, 6, 1 (2020). DOI: 10.1016/j.jmat.2019.11.001

[194] C.-C. Lee. Thin Solid Films, 544, 443 (2013). DOI: $10.1016 /$ j.tsf.2013.02.084

[195] D. Faurie, P.-O. Renault, E. Le Bourhis, G. Geandier, P. Goudeau, D. Thiaudiere. Appl. Surf. Sci., 306, 70 (2014). DOI: 10.1016/j.apsusc.2014.02.032

[196] A.A. Vereschaka, S.N. Grigoriev, N.N. Sitnikov, G.V. Oganyan, A. Batako. Surf. Coat. Technol., 332, 198 (2017). DOI: 10.1016/j.surfcoat.2017.10.027

[197] K. Bobzin, T. Brögelmann, N.C. Kruppe, M. Carlet. Surf. Coat. Technol., 385, 125370 (2020). DOI: 10.1016/j.surfcoat.2020.125370

[198] A. Grill. Diamond Relat. Mater., 12, 166 (2003). DOI: 10.1016/S0925-9635(03)00018-9

[199] M. Qadir, Y. Li, C. Wen. Acta Biomater., 89, 14 (2019). DOI: 10.1016/j.actbio.2019.03.006

[200] H. Tian, N. Saka, E. Rabinowicz. Wear, 142, 57 (1991). DOI: 10.1016/0043-1648(91)90152-K

[201] Н.К. Мышкин, В.В. Кончиц, М. Браунович. Электрические контакты. (Издательский дом „Интеллект“, Долгопрудный, 2008).

[202] E.V. Torskaya, A.M. Merzin, I.V. Mosyagina, Yu.V. Kornev. Phys. Mesomech., 21, 475 (2018). DOI: $10.1134 / \mathrm{S} 1029959918060012$

[203] Q. Liu, T. He, W.Y. Guo, Y. Baia, Y.S. Ma, Z.D. Chang, H.B. Liu, Y.X. Zhou, F. Ding, Y.W. Sun, Z.F. Han, J.J. Tang. Surf. Coat. Technol., 370, 362 (2019). DOI: 10.1016/j.surfcoat.2019.03.044

[204] R. Colaço In: Fundamentals of friction and wear on the nanoscale, ed. by E. Gnecco, E. Meyer (Springer, Heidelberg, 2007). P. 453.

[205] M.A. Fortes, R. Colaço, M.F. Vaz. Wear, 230, 1 (1999). DOI: $10.1016 / \mathrm{S} 0043-1648(99) 00086-1$ 